\title{
ASSESSMENT OF ENVIRONMENTAL EXPOSURE VULNERABILITY IN TORONTO PUBLIC HOUSING: A GIS AND ENVIRONMENTAL JUSTICE ANALYSIS
}

\author{
by \\ NICOLE SLATTERY \\ Bachelor of Science, Dalhousie University, 2018
}

\author{
An MRP presented to Ryerson University \\ in partial fulfillment of the requirements for the degree of \\ Master of Spatial Analysis \\ in the program of \\ Spatial Analysis
}

Toronto, Ontario, Canada

(C) Nicole Slattery, 2019 


\section{AUTHOR'S DECLARATION FOR ELECTRONIC SUBMISSION OF AN MRP}

I hereby declare that I am the sole author of this MRP. This is a true copy of the MRP, including any required final revisions.

I authorize Ryerson University to lend this MRP to other institutions or individuals for the purpose of scholarly research.

I further authorize Ryerson University to reproduce this MRP by photocopying or by other means, in total or in part, at the request of other institutions or individuals for the purpose of scholarly research.

I understand that my MRP may be made electronically available to the public. 
Assessment of Environmental Exposure Vulnerability in Toronto Public Housing: A GIS and Environmental Justice Analysis

Nicole Slattery

Master of Spatial Analysis

Ryerson University, 2019

\section{ABSTRACT}

This paper explores environmental exposure levels across the city of Toronto, with a novel focus on Toronto public housing. Research has shown that environmental exposures are associated with negative effects on the health of populations. Using spatial and statistical methods, the objective of the research is to: (1) measure environmental exposures across the city of Toronto; (2) determine if public housing units are more vulnerable to environmental exposures and, (3) assess if environmental exposure can predict the location of public housing. The results of this study suggest that the public housing dissemination areas are within areas of higher vulnerability than other dissemination areas in Toronto. The population in public housing are disproportionately affected by environmental exposures and are at risk of the associated harmful health implications. This study provides spatial patterns of environmental exposure vulnerability across Toronto, in order to inform planning and revitalization of public housing developments in Toronto. 


\section{ACKNOWLEDGEMENTS}

I would like to warmly thank my supervisors Dr. Sara Edge \& Dr. Tor Oiamo for their dedicated guidance and support throughout this MRP process and school year. Thank you for your valuable insight provided consistently in order to help me with this paper's research, analysis and writing. I would also like to thank the Canadian Urban Environmental Health Research Consortium (CANUE) for their quick distribution of the necessary data to complete this study.

Finally, I would like to thank my family, friends and Patrick for their loving support throughout this past year... I wouldn't have been able to do any of this without you. 


\section{TABLE OF CONTENTS}

ABSTRACT

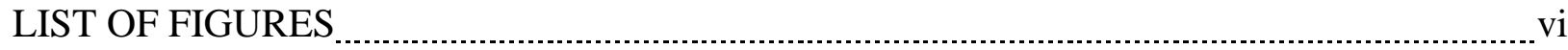

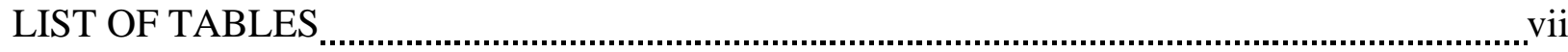

1. INTRODUCTION..................................................................................................................... 1

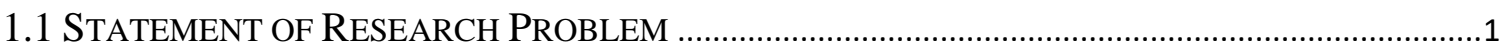

1.2 RESEARCH OBJECTIVES.............................................................................................................

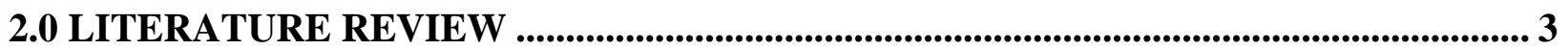

2.1 BACKGROUND INFORMATION ................................................................................................

2.2 ENVIRONMENTAL EXPOSURES AND HEALTH OUTCOMES ……………………………………...

2.3 IMPORTANCE OF GIS IN ENVIRONMENTAL EXPOSURE ANALYSIS ...........................................

2.4 THEORETICAL FRAMEWORK: ENVIRONMENTAL JUSTICE....................................................10

2.5 GIS AND ENVIRONMENTAL JUSTICE........................................................................................11

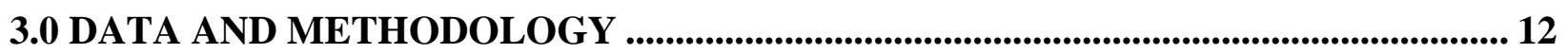

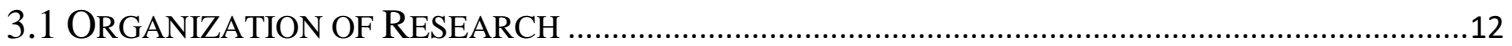

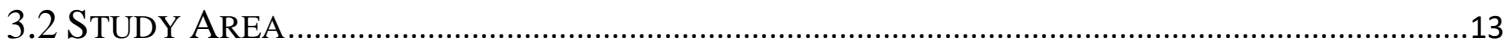

3.3 SUMMARY OF DATA AND PRE-PROCESSING …………………………………………......

3.4 SPATIAL ANALYSIS …………………………………………………………………….....

3.4.1 GREENSPACE ACCESSIBILITY .............................................................................................18

3.4.2 VULNERABILITY ASSESSMENT ………………………………………………………….....19

3.5 STATISTICAL ANALYSIS …………………………………………………………....22

3.5.1 STATISTICAL TESTING: T-TEST AND CHI-SQUARE...........................................................22

3.5.2 LOGISTIC REGRESSION......................................................................................................22

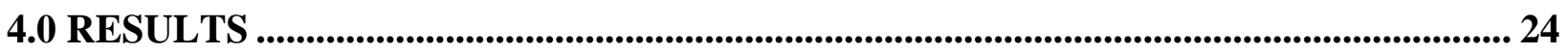

4.1 Public Housing Data ……………………………………………………………....24

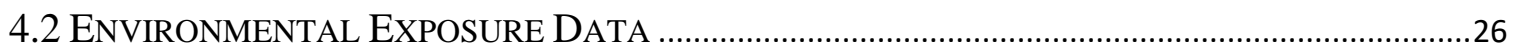

4.3 GREENSPACE ACCESSIBILITY ...............................................................................................

4.4 VULNERABILITY ASSESSMENT ................................................................................................

4.5 STATISTICAL ANALYSIS: DESCRIPTIVE \& BIVARIATE RESULTS .............................................

4.6 STATISTICAL ANALYSIS: LOGISTIC REGRESSION ……………………………………….......

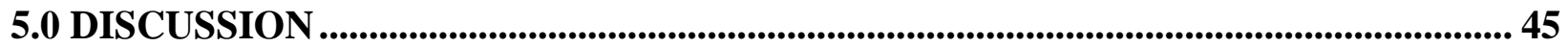

6.0 CONCLUSION AND RECOMMENDATIONS................................................................. 51

REFERENCES …………………………………………………………………………. 


\section{LIST OF FIGURES}

Figure 3.2.1 Map of the study area Toronto, Ontario

Figure 4.1.1. The geographic locations of public housing developments in relation to medium household income (\$) across Toronto dissemination areas

Figure 4.1.2. The geographic locations of public housing developments in relation to populations of visible minorities (count) across Toronto dissemination areas.

Figure 4.2.1. Maximum nitrogen dioxide estimates of the dissemination areas in parts per billion, displayed by quintiles, across Toronto dissemination areas.

Figure 4.2.2. Maximum traffic related noise levels (dBA) for nighttime hours, displayed by quintiles, across Toronto dissemination areas

Figure 4.2.3. Social deprivation factor scores by quintiles, where quintile 1 represents the least deprived (most privileged) and quintile 5 represents the most deprived. The factor scores are displayed across Toronto dissemination areas.

Figure 4.2.4. Material deprivation factor scores by quintiles, where quintile 1 represents the least deprived (most privileged) and quintile 5 represents the most deprived. The factor scores are displayed across Toronto dissemination areas.

Figure 4.3.1. The total cover (\%) of accessible public greenspace across Toronto dissemination areas, displayed by quintile.

Figure 4.4.1. Vulnerability index scores of Toronto dissemination areas to environmental exposures to air pollution, noise pollution, lack of accessible greenspace, and material and social deprivation.

Figure 4.4.2. The geographic location of pubic housing developments in relation to the vulnerability index scores of Toronto dissemination areas.

Figure 4.5.1. Box plot of the distribution characteristics of the chosen environmental exposure variables: air pollution, noise pollution, greenspace, and social and material deprivation 36 


\section{LIST OF TABLES}

Tables 3.3.1 Justification for data variables selected for the analysis

Table 3.4.1. Reclassification of exposure variable values

Table 4.4.1. Range and associated risk of vulnerability

Table 4.5.1. Descriptive analysis statistics of exposure variables: population size, mean, standard deviation, minimum and maximum. 35

Table 4.5.2. Independent samples T-Test 37

Table 4.5.3. Group statistics 37

Table 4.5.4. Processing summary: Chi Square test of categorical data 38

Table 4.5.5(a) Crosstabulation of Housing \& Greenspace Cover 38

Table 4.5.5(b) Chi Square test of Housing \& Greenspace Cover. 39

Table 4.5.6(a) Crosstabulation of Housing \& Social Deprivation 39

Table 4.5.6(b) Chi Square test of Housing \& Social Deprivation 39

Table 4.5.7(a) Crosstabulation of Housing \& Material Deprivation 39

Table 4.5.7(b) Chi Square test of Housing \& Material Deprivation 40

Table 4.6.1. Logistic Regression: Categorical variable reclassification for the predictor variables .

Table 4.6.2. Logistic Regression: Model predicting the presence of public housing in dissemination areas across Toronto, using the predictor variables 43

Table 4.6.3. Logistic Regression: Classification table 45 


\section{INTRODUCTION}

\subsection{Statement of Research Problem}

The need for quality, low income public housing has become a crisis in Canada (Florida, 2018; Pagliaro, 2017; Pagliaro \& Mathieu, 2019; Skelton, 1996). Public housing is government funded and operated subsidized housing, sometimes specified as community or social housing (Canadian Mortgage and Housing Corporation (CMHC), n.d.). Public housing aims to provide affordable housing for disadvantaged populations, due to existing economic and housing disparities (CMHC, n.d.). The city of Toronto has one of the least affordable housing markets in Canada (RBC Economics, 2016), which has increased pressures on the city's public housing system (Toronto Public Health, 2016). A study by Toronto Public Health (2016), indicated that one in four Canadian households are spending 30\% or more of their before-tax income on shelter costs. The high cost of housing in Toronto has led to an increased demand for subsidized public housing, well above the city's current capacity (Toronto Public Health, 2016). In 2003, over 70,000 families had been placed on the Toronto Community Housing Corporation waiting list; today, the waiting list has increased to a wait time of 12 years for subsidized housing (Pagliaro \& Mathieu, 2019; Vakili-Zad, 2004).

This issue spans across Canada, however, the need is felt most strongly within densely populated city centers like Toronto, where homelessness and housing conditions have become particularly concerning (Pagliaro, 2017). It is estimated that over 230,000 people will experience homelessness each year in Canada, and in Toronto specifically, more than 5000 people are accessing shelters each night, with many more ending up on the streets (Beder \& Ritts, 2017).

Lack of funding, availability and quality of public housing has generated concerns about the environmental conditions within public housing units and the surrounding areas of cities in which they are situated (CMHC, n.d.; Pagliaro, 2017). If vulnerable populations living in public 
housing are being disproportionately affected by adverse environmental exposures, then the Toronto public housing crisis could be defined as an environmental justice issue. Environmental exposures across the city have been studied extensively; however, no research has focused on the environmental exposure surrounding Toronto public housing developments.

\subsection{Research Objectives}

This research aims to analyze neighbourhood environmental exposure and stressors around Toronto public housing projects. Specifically, this study seeks to test the hypothesis that public housing residents are disproportionately exposed to high levels of environmental stressors. The specific objectives of the study are to:

1. Characterize the levels of environmental stressor vulnerability throughout the city of Toronto, by dissemination areas; and

2. Determine if locations of public housing are likely to have higher environmental exposure than other areas across the city of Toronto, and

3. Assess whether environmental exposure can predict the location of public housing.

This study will elucidate the environmental disadvantages of public housing units and their immediate neighbourhood environment throughout Toronto dissemination areas, which can be associated with potential health outcomes. Vulnerability and exposure have been defined differently within other fields of research (Angelsen \& Dokken, 2018; Oulahen et al., 2018); however, within the context of this study, vulnerability is defined as a function of environmental exposure. Vulnerability includes exposure and encompasses the susceptibility of harm due to the measured exposure levels (Angelsen \& Dokken, 2018). The study enriches the broader research, as there are currently many gaps in studies related to neighbourhood environment, health and public housing associations in Toronto. The findings of this research highlight issues concerning 
the surrounding environment of public housing projects established across Toronto and implications for resident wellbeing. As well, point towards alterative or additional sites for future public housing projects, in order to rectify environmental injustices for populations in public housing.

\subsection{LITERATURE REVIEW}

The literature review will provide background information on the history of public housing. The review also explores existing literature on environmental exposures; the use of GIS in environmental exposure analysis, theoretical perspectives on environmental justice, and a review of studies adopting spatial analysis approaches in environmental justice research.

\subsection{Background Information}

The first government funded community housing properties were built after World War II, when adequate affordable housing for returning Canadian soldiers and their families was limited (CMHC, n.d.; Skelton,1996.). In the face of continued affordable housing needs and shortages, the Canadian government funded hundreds of housing units for low income families throughout the 1950s (CMHC, n.d.). By the 1980s, five thousand public housing projects were established across Canada, majorly concentrated in Ontario (Schlosberg, 2007). Simultaneously starting in the 1980s, the Canadian government shifted to prioritize the private sector over the public sector, as Canada underwent a neoliberalism transformation and began implementing cuts to social and health spending (Hackworth \& Moriah, 2006). This included withdrawing funding for municipal public housing projects (CMHC, n.d.), which downloaded the financial and social burden of housing programs onto municipal governments (Young \& Bruce, 2003). The simple cutback in funding for public housing developments effectively offloaded the responsibility of the most vulnerable populations in the province to municipalities (Hackworth \& Moriah, 2006). Canadian 
municipalities were left to deal with the critical and poor-quality housing units without the money needed to cover repairs (Pagliaro, 2017). The city of Toronto established the Toronto Community Housing Corporation (TCHC) in 2002, with plans to redevelop and revitalize public housing within the city (TCHC, 2016). However, data shows that of the approximate 360 public housing units across Toronto, 222 are considered in 'poor' condition with many categorized under critical condition (Pagliaro, 2017).

Limited funding for substandard public housing developments has been linked to poor builtenvironment and neighbourhood quality (Boston College, 2013; DeLuca, Garboden \& Rosenblatt, 2013). More specifically, a study by DeLuca, Garboden \& Rosenblatt (2013) explored how housing policies shape the residential locations of low-income minority families in America. They found that lack of funding and policy created barriers and challenges for low income minority families to finding quality affordable housing in middle class neighbourhoods (DeLuca, Garboden \& Rosenblatt, 2013). The majority of public housing units were in burdensome conditions or within low income neighbourhoods. Throughout Toronto dozens of public housing units are in critical condition; however, it is predicted that within the next 5 years over half of the city's public housing developments will be in critical condition without additional funding for repair (Pagliaro, 2017). This statistic was calculated using a standard facility condition index, used to assess the relative condition of facilities (Ontario, 2016). This index considers the facility as an asset; whether or not the cost of repair may exceed current property replacement value (Bart, 2016). This index does not consider resident and environmental health within the scope of the calculated quality. Despite insight from existing research, there are insufficient studies exploring the quality of Canadian substandard public housing conditions and associated health stressors or implications. Throughout the related academic literature, environmental stress exposure exacted upon residents 
of public housing has only been studied from a social qualitative perspective, with residents reporting experiences of noisy, dirty, small, isolated and pest-infested housing conditions within housing and shelter developments in Canada. This particular study focused on the built environmental quality of individual public housing units (Sylvestre, 2018). This current study will focus more specifically on the neighbourhood environmental exposures inflicted upon residents of public housing, as geographic location is a key known determinant of environmental exposure to social and physical stressors, which are likely to affect health (Poulter et al., 2015). Furthermore, no previous studies have monitored geographical inequalities in social and physical environments throughout the city of Toronto, with emphasis on the environmental exposure of public housing neighbourhoods.

\subsection{Environmental Exposures and Health Outcomes}

The housing environment is an engine of social inequality, that has both material and psychosocial dimensions, that contribute to health disparities amongst populations (Dunn, 2002; Maroko, Riley \& Malcolm, 2013; Poulter et al., 2015). For instance, Dunn has focused on adult residents of households in Vancouver, Canada and their self-reported measure of housing quality (2002). He found that housing environment are significant predictors of self-reported physical and mental health (Dunn, 2002). Housing environments include not only the built-environmental quality of the housing units, but also the surrounding neighbourhood environment (Dunn, 2002; Jones-Rounds et al., 2014). A landmark study found that the most significant risk factor accounting for health outcomes was neighbourhood environment (Olden et al., 2014). In this study, neighbourhood environment was defined as the surrounding physical, social and economic setting in which residents were situated. Neighbourhood environment has been measured by environmental exposure in previous studies. Abundant research has shown that obesity, mental health and other health outcomes are risk factors related to environmental stressor exposure 
(Helbich, 2018; Ibem, Opoko \& Aduwo, 2017; Jarrett et al., 2005; Jarrett, 2001; Vlachokostas et al., 2013). Ongoing environmental exposures such as air pollution, noise pollution, toxic substances and socioeconomic status have given rise to concerns about human health (Vlachokostas et al., 2013). There are other studies that have shown that greenspace, noise and housing conditions might trigger mental health disorders or facilitate stress reduction (Helbich, 2018). This research advances our knowledge of environmental exposure and health outcomes through focusing on Canadian neighbourhood environmental exposure and public housing specifically. This is important given the majority of residents in public housing households are vulnerable or minority populations (TCHC, 2017), and the cumulative disadvantage of low socioeconomic status can further undermine health and wellbeing within substandard or unhealthy environments (Chueng \& Jim, 2019; Shmool et al., 2014).

Air pollution is a major environmental risk to health (WHO, 2018) and has been linked to high burden of disease in many countries. The primary contributor to air pollution in urban centers has been determined to be local vehicular traffic (Parent et al., 2013; Maantay, 2007). Nitrogen dioxide, more specifically, has been shown to be a marker for traffic related pollution in neighbourhoods (Brook et al., 2004; Fuks et al., 2017; Parent et al., 2013). The World Health Organization currently outlines the maximum value of 40 micrograms per cubic meter of nitrogen dioxide (annual mean) in order to protect the public from health effects of the gas (WHO, 2018).

Noise pollution has been linked to sleep disorders, lack of concentration, mental health, cardiovascular disease and overall decreased wellbeing (Babisch, 2007; Basner et al., 2014; Stansfeld, 2015; Lakes, Bruckner \& Kramer, 2013; Munzel et al., 2018; WHO, 2018). Common sources of noise within urban centers like Toronto include road traffic noise, railway noise and aircraft noise (WHO, 2018). Road traffic noise is of particular importance, as more than $30 \%$ of 
the population of Europe were exposed to high road traffic noise linked with severe sleep disturbance and adverse health effects (Ma et al. 2018). Traffic accounts for $60 \%$ of the noise pollution in Toronto (Oiamo et al., 2018; Toronto Public Health, 2017). This indicates the importance of studying traffic related noise pollution. The study by Ma et al. (2018) found that perceived higher noise-pollution exposure is significantly associated with worse mental health. The world health organization strongly recommends reducing noise levels from traffic related sources to below 53 decibels. It associates noise levels above this level with adverse health effects. Furthermore, noise pollution has been identified as a serious harm to human health (Bilasco et al., 2017; Ma et al., 2018; WHO, n.d.) and is defined as the most significant environmental stressor associated with disease (Lakes, Bruckner \& Kramer, 2013). GIS has been previously used to map air and noise pollution in order to improve the exposure estimates for justice and health analysis (Bilasco et al., 2017; Jerrett et al., 2001; Sheppard et al., 1999). However, this study is one of the first to focus on exposure estimates of air and noise pollution for public housing communities in Toronto.

The socio-economic status of a neighborhood includes material and social characteristics, such as underinvestment in neighbourhood goods and services, crime, social isolation, income, exposure to pollutants...etc. (Ross, Oliver \& Villeneuve, 2013). Studies have found that living in socially and materially deprived Canadian neighbourhoods is associated with elevated mortality risk (Ross, Olivier \& Villeneuve, 2013). As well, other studies have linked materially deprived and ethnically concentrated neighbourhoods with higher glucose levels in pregnant women (Sampson, Dasgupta \& Ross, 2014). Across neighbourhoods the material and social resources available to populations are unequally distributed and are amplifiers to health inequalities (Sampson, Dasgupta \& Ross, 2014). Very little literature has focused on utilizing GIS to measure 
and analyze material and social deprivation across geography. Therefore, studying the distributional justice issues related with Material and Social Deprivation index (MSDI) across the city of Toronto using GIS will fill very large gaps within the associated literature. As such, the MSDI will be one of the measures assessed in this study. The deprivation index covers approximately $98 \%$ of the Canadian population by dissemination areas (Matheson, 2017). Material deprivation refers to the lack of goods and conveniences which are associated with modern life (Statistics Canada, n.d.). Social deprivation refers to the fragility of the social network which includes family and community (Statistics Canada, n.d.). The index is calculated using six socio-economic indicators: no high school diploma, employment, income, being widowed, separated or divorced, living alone and being a lone-parent family (Statistics Canada, n.d.). The indicators chosen for the index have known links to health outcomes and have been previously used as geographic proxies (Matheson, 2017).

Greenspace has also been chosen as a measure, and is defined as natural and landscaped areas that are both publicly or privately owned (Taylor \& Hochuli, 2016). Greenspace has increasingly become an area of focus to researchers interested in examining disparities in access to environmental amenities (Heckert, 2013). There are many benefits associated with living in close proximity to urban green areas, such as improved air quality, better physical health and better mental health (Heckert, 2013; Taylor \& Hochuli, 2016; World Health Organization, 2016). Toronto Public Health (2013) identified that the proximity of greenspace to vulnerable populations is particularly important and the health benefits are more profound for these low socioeconomic groups. One hectare of greenspace was chosen as a threshold within this study, because of the lack of availability for some residents to access greenspace in highly urbanized and populated cities, as it was in the study by Evergreen (2014). Additionally, the World Health Organization (2016) 
recommends living within 15 minutes from accessible greenspace. GIS has been used in past literature to determine the accessibility of greenspace (Evergreen, 2014). This research will follow similar methods; however, it will place emphasis on populations of public housing.

\subsection{Importance of GIS in Environmental Exposure Analysis}

Geographic Information Systems (GIS) and spatial analysis techniques have been used to study health and environmental issues extensively (Fisher et al., 2005; Jarrett et al., 2005; Maantay, 2007; Sheppard et al., 1999). GIS is an important tool that allows for large quantities of information to be analyzed within a geographic context (Vine et al., 1997). GIS technology has been used to combine multiple layers of geographic data concerning environmental exposures, such as industrial toxic pollution sites, and population characteristics such as race or median household income, in order to analyze the geographic proximity between pollution and population characteristics (Sheppard et al., 1999). Associations between proximity to environmental exposure and health were prevalent (Sheppard et al., 1999). Jarrett et al. (2005) utilized spatial analysis techniques to determine particulate exposure throughout Hamilton, Ontario in relation to social factors and neighbourhood environmental perceptions. This research, like the majority of existing literature, has focused on neighbourhood environmental exposures broadly. Very little research has utilized GIS and spatial analysis to analyze the spatial relationships between multiple sources of environmental stressors and vulnerable populations in Toronto. Consequently, a remaining question is whether multiple sources of environmental stressors have an additive effect on populations (Evans \& Cohen, 1982). The study by Choudhary, Boori \& Kupriyanov (2018), examined the vulnerability of populations based on multiple layers of environmental variables of land use classification, using geographic information system and remote sensing. Vulnerability assessments are commonly based on indices generated from measured characteristics and provide a comprehensive analysis of the geographic areas at risk to environmental exposure and, 
distribution of human health impacts (Burgos et al., 2017). This research will utilize similar methods to characterize dissemination areas by levels of environmental exposure and therefore, assess the vulnerability of populations within the dissemination areas, with a novel focus on public housing populations. Within previous studies, vulnerability was a function of exposure; where higher levels of environmental exposure insinuated a higher vulnerability to negative health outcomes (Choudhary, Boori \& Kupriyanov, 2018). GIS will aid to facilitate comparisons between exposure levels within public housing environments and non-public housing environments (Shmool et al., 2014). Previous literature has combined GIS based analysis with regression analysis to assess the degree or significance of the relationships between exposure and geodemographic characteristics (Sheppard et al., 1999). This current research will integrate geostatistical methods such as logistic regression, in order to determine if environmental exposures can predict the locations of public housing in Toronto. This is important in order to analyze neighbourhood environmental exposures and establish if they determine if one lives in public housing.

\subsection{Theoretical Framework: Environmental Justice}

The overriding theory that will be used when studying the spatial distribution of environmental stressors, is environmental justice. Environmental justice emerged as a normative concept and social movement in the 1980s (Enrstson, 2012). In the 1970s, researchers started to explore the correlations between social class status and air quality in the United States (Pellow, 2014). The focus of the research expanded from social class to race and furthermore from air quality to other environmental exposures (Pellow, 2014). The framework addresses the underlying causes that may contribute to and produce environmental inequities, with the goal of promoting fairness amongst all people regardless of their socioeconomic background (LaToria, Buchanan \& Sharunda, 2019). There are several types of environmental justice theory, such as distributional 
justice and procedural justice. Distributive environmental justice is concerned with the distribution of environmental, social and economic benefits or burdens amongst groups of individuals (Kurtz, 2003; Lakes, Bruckner \& Kramer, 2013; Pellow, 2016; Svarstad et al., 2011). Whereas, procedural justice focuses on participation in environmental decision-making; where all affected people should have the possibility to be informed, express their opinions and influence decision making (Svarstad et al., 2011). While both types of environmental justice are applicable to the issue of environmental exposures and public housing in Toronto, this study will predominately contribute to knowledge on distribution injustice. The theory focuses on distribution of environmental goods or 'bads' and, less environmental protection; which usually disproportionately negatively affects low income, indigenous and minority communities (Schlosberg, 2007). This study will integrate GIS and geostatistics through a distributional environmental justice lens, to examine environmental stressors in relation to public housing communities in Toronto. These communities are confronted with higher burden of environmental stressors and exposure; therefore, the distribution of burden primarily affects them (Apparcicia, Seguin \& Naud, 2008; Cheung \& Jim, 2019; TCHC, 2017).

\subsection{GIS and Environmental Justice}

A study by Jelks et al. (2018) found that geographic information systems aided researchers in creating spatial narratives to help advance environmental justice action within communities. It has been recognized that disadvantaged communities suffer disproportionately from environmental stressors (Chueng \& Jim, 2019; Ernstson, 2012; Mohai, Pellow \& Roberts, 2009; Scholsberg, 2007; Shmool et al., 2014). This highlights the importance of examining the location of public housing projects in Toronto, where many vulnerable populations reside, in relation to burdens of high environmental stress. Maroko et al. (2013) quantified the geographic distribution of neighbourhood stressors and environmental injustices, in relation to social and built 
environmental features in the Bronx, New York. The study utilized environmental justice to understand how biological, physical and social attributes of communities, shape health outcomes across landscapes (Maroko et al., 2013). This is important in order to identify and enhance the visibility of injustices, as well as assist in advocacy against future injustices.

In environmental justice research, exposures that will be considered as environmental stressors must be identified, in order to assess if certain populations are disproportionately being affected (Maantay, 2007). Throughout current literature, the geographic distribution of air quality, noise, socioeconomic and built environmental exposures in relation to population health have been studied extensively (Halperin, 2014; Maantay, 2007; Ma et al., 2018; Parent et al., 2013; Ross, Oliver \& Villeneuve, 2013; Sampson, Dasgupta \& Ross, 2014; Shmool et al., 2014). No research has focused on the environmental exposure of these variables around Toronto public housing projects.

\subsection{DATA AND METHODOLOGY}

\subsection{Organization of Research}

The research conducted in this paper follows four major stages. Firstly, the study context, specifically the City of Toronto is described. The next stage relates to the procurement and preprocessing of the environmental exposure data for the city of Toronto. The second stage employs spatial analysis to calculate the vulnerability of DA's to the selected environmental exposures, in relation to public housing developments. This entailed calculating greenspace accessibility and a vulnerability index for the DA's. The third stage utilizes statistical analysis of the environmental variables to determine if they can be used to predict whether or not dissemination areas contain public housing. 


\subsection{Study Area}

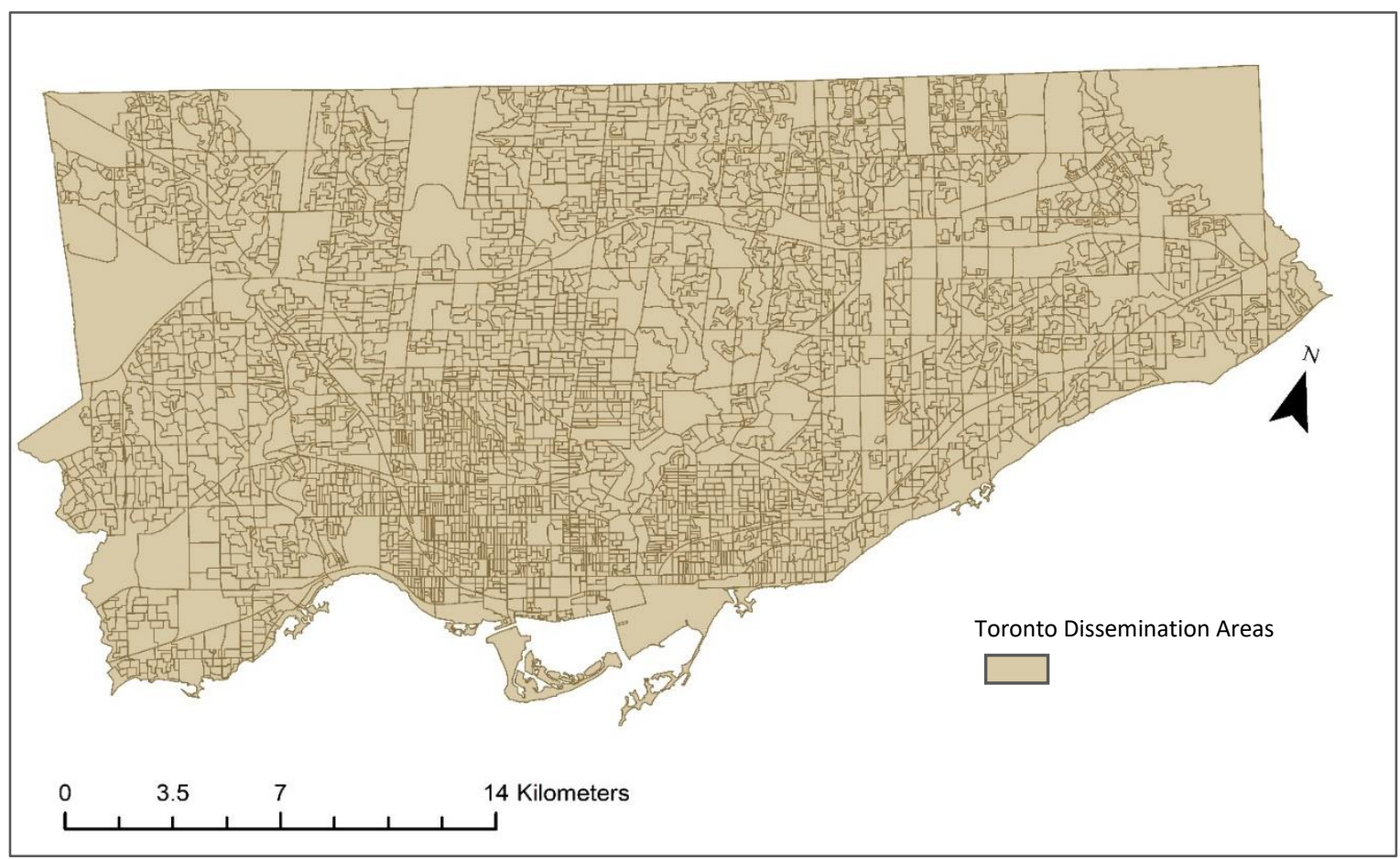

Figure 3.2.1: Map of the study area Toronto, ON, shown by dissemination areas.

The city of Toronto is the capital of the province of Ontario, located in of southern Ontario.

Toronto is an excellent study site for this research, as the majority of Canadian public housing units are located in Toronto (Schlosberg, 2007). Toronto is the largest metropolitan area in Ontario, spanning 630 square kilometers and is the most populous city in Canada (Statistics Canada, 2016). There are 1054 public housing projects (with 6 or more units) across the city of Toronto, largely concentrated within the downtown core. However, only 320 dissemination areas in Toronto contain one or more public housing projects. Currently the Toronto Community Housing Corporation is in a state of crisis (Mathieu \& Rider, 2018), as hundreds of thousands are waiting for a place in the public housing system and housing affordability is a rising issue. This highlights the importance of studying public housing in Toronto; as it addresses the current concerns of housing and health quality associated with the substandard housing developments. 
The analysis of the city of Toronto utilized a dissemination area (DA) level of geographic detail, in order to aggregate the variables within this research; due to accessibility and data restrictions. This research assumes that individual housing unit environments are realized within the respective larger DA environment. It assumes the geographic principal that near areas are more similar than far areas, and thus the dissemination areas encompass the exposures present at public housing units (Shmool et al., 2014). The environmental exposure datasets were acquired as nonspatial data formats; therefore, they were spatially displayed in order to observe patterns throughout Toronto dissemination areas. It is assumed that the values selected within the DA's for this analysis encompass the spatial variability of exposure that individuals within the dissemination areas experience during the majority of time (Nuckols, Ward \& Jarup, 2004). Typically, in Canada, dissemination areas contain between 400 to 700 people (Statistics Canada, 2016). DA's are small areas composed of one or two neighbourhood blocks and are the smallest standard geographic area for census data in Canada (Statistics Canada, n.d.). There are 3685 DA's located throughout the city of Toronto, with an average population of 699. Dissemination areas are uniform in terms of population size, they were selected as this avoids data suppression. However, there are exceptions, as some DA's contain a population of 0 and some much higher than 700 (Statistics Canada, 2016).

\subsection{Summary of Data and Pre-Processing}

The data in this study is very important for the analysis of studying the spatial distribution, statistical significance and relationship amongst variables. Refer to Table 3.3.1 for justification and details about data included in this analysis. The datasets that were used in this study were obtained from multiple sources including: the Canadian Urban Environmental Health Research Consortium (CANUE), Statistics Canada, Toronto Open Data and Dr. Tor Oiamo. Data from CANUE provided information on the levels of environmental exposure across Toronto and the location and characteristics of postal code locations. Data from Statistics Canada provided 
information about geographic boundaries of dissemination areas. Furthermore, Toronto Open Data provided information about greenspace and public housing locations and descriptions and, finally Dr. Tor Oiamo provided noise data information for the City of Toronto. It is important to note that the Toronto Public Housing dataset only contained buildings larger than 6 units. This introduces some error, as the location of smaller public housing developments were not available for the analysis. As well, the dataset was assembled in 2013 therefore some newer developments and reconstructions are omitted from the data.

The nitrogen dioxide concentration data were collected from 2006 national air pollution surveillance (NAPS) satellite monitoring (Hystad et al., 2011; Weichenthal, Pinault \& Burnett, 2017); and was estimated using land use regression modelling (CANUE, n.d.). The estimates were collected on the postal code level throughout the city of Toronto. The material and social deprivation index dataset, from CANUE, was compiled from the 2016 Statistics Canada census (Pampalon, 2012). The data were spatially joined to the dissemination areas. The noise pollution levels were measured using Noise Sentry RT sound level meter data logger (Oiamo et al., 2018). The noise measurements were converted to sound power levels, and were temporally and spatially continuous data (Oiamo et al., 2018). Finally, the boundary and locations of greenspace/parks dataset were compiled by Toronto Parks, Forestry and Recreation (City of Toronto, 2019). 
3.3.1 Justification and details of datasets used in the analysis.

\begin{tabular}{|c|c|c|c|c|c|c|c|}
\hline Dataset Name & $\begin{array}{l}\text { Data } \\
\text { Type }\end{array}$ & $\begin{array}{l}\text { Categorie } \\
\mathrm{s}\end{array}$ & $\begin{array}{l}\text { Projectio } \\
\mathrm{n}\end{array}$ & Description & Justification & $\begin{array}{l}\text { Spatial } \\
\text { Enabled } \\
?\end{array}$ & Source \\
\hline $\begin{array}{l}\text { Dissemination } \\
\text { Area }\end{array}$ & $\begin{array}{l}\text { Shapefi } \\
\text { le }\end{array}$ & N/A & WGS84 & $\begin{array}{l}\text { Cartographic } \\
\text { boundary file } \\
\text { of } \\
\text { disseminatio } \\
\mathrm{n} \text { areas for } \\
\text { Canada. }\end{array}$ & $\begin{array}{l}\text { The chosen } \\
\text { geography } \\
\text { for this study. }\end{array}$ & YES & $\begin{array}{l}\text { Statistics } \\
\text { Canada, } 2011 .\end{array}$ \\
\hline Postal Codes & $\begin{array}{l}\text { Comm } \\
\text { a } \\
\text { separat } \\
\text { ed } \\
\text { values }\end{array}$ & N/A & N/A & $\begin{array}{l}\text { Postal Code } \\
\text { locations, } \\
\text { descriptive } \\
\text { attributes } \\
\text { and } \\
\text { identifiers. }\end{array}$ & $\begin{array}{l}\text { The spatial } \\
\text { resolution of } \\
\text { acquired } \\
\text { environmenta } \\
\text { l exposure } \\
\text { data. }\end{array}$ & NO & $\begin{array}{l}\text { CANUE, } \\
2015\end{array}$ \\
\hline $\begin{array}{l}\text { Toronto } \\
\text { Community } \\
\text { Housing Data }\end{array}$ & $\begin{array}{l}\text { Shapefi } \\
\text { le }\end{array}$ & N/A & $\begin{array}{l}\text { WGS84 } \\
\text { Latitude/ } \\
\text { Longitud } \\
\text { e }\end{array}$ & $\begin{array}{l}\text { Toronto } \\
\text { Community } \\
\text { Housing data } \\
\text { including } \\
\text { development } \\
\text { s larger than } \\
5 \text { units, } \\
\text { descriptive } \\
\text { attributes } \\
\text { and location. }\end{array}$ & $\begin{array}{l}\text { The location } \\
\text { of public } \\
\text { housing for } \\
\text { analysis. }\end{array}$ & YES & $\begin{array}{l}\text { Open Data } \\
\text { Toronto, } \\
\text { Shelter, } \\
\text { Support \& } \\
\text { Housing, } \\
2013 .\end{array}$ \\
\hline Parks & $\begin{array}{l}\text { Shapefi } \\
\text { le }\end{array}$ & N/A & $\begin{array}{l}\text { WGS84 } \\
\text { Latitude/ } \\
\text { Longitud } \\
\text { e }\end{array}$ & $\begin{array}{l}\text { Boundaries } \\
\text { and park } \\
\text { names for } \\
\text { public green } \\
\text { areas within } \\
\text { the City of } \\
\text { Toronto. }\end{array}$ & $\begin{array}{l}\text { Acquired in } \\
\text { order to } \\
\text { calculate } \\
\text { accessibility } \\
\text { to greenspace } \\
\text { by } \\
\text { Disseminatio } \\
\text { n Area. }\end{array}$ & YES & $\begin{array}{l}\text { Open Data } \\
\text { Toronto, } \\
\text { Parks, } \\
\text { Forestry \& } \\
\text { Recreation, } \\
2018 .\end{array}$ \\
\hline $\begin{array}{l}\text { Material and } \\
\text { Social } \\
\text { Deprivation } \\
\text { Index (MSDI) }\end{array}$ & $\begin{array}{l}\text { Comm } \\
\text { a } \\
\text { Separat } \\
\text { ed } \\
\text { values }\end{array}$ & $\begin{array}{l}1 \\
2 \\
3 \\
4 \\
5\end{array}$ & N/A & $\begin{array}{l}\text { Material and } \\
\text { Social factor } \\
\text { score } \\
\text { quintiles } \\
\text { within the } \\
\text { census } \\
\text { metropolitan } \\
\text { area by } \\
\text { disseminatio } \\
\text { n areas. }\end{array}$ & $\begin{array}{l}\text { Used to } \\
\text { measure area } \\
\text { based socio- } \\
\text { economic } \\
\text { information. }\end{array}$ & $\mathrm{NO}$ & $\begin{array}{l}\text { CANUE, } \\
2016\end{array}$ \\
\hline $\begin{array}{l}\text { Nitrogen } \\
\text { Dioxide }\end{array}$ & Excel & N/A & N/A & $\begin{array}{l}\text { Monthly } \\
\text { nitrogen } \\
\text { dioxide } \\
\text { concentratio } \\
\mathrm{n} \text { (ppb) } \\
\text { averages by } \\
\text { postal code. }\end{array}$ & $\begin{array}{l}\text { Determine } \\
\text { the air quality } \\
\text { of } \\
\text { dissemination } \\
\text { areas. }\end{array}$ & $\mathrm{NO}$ & $\begin{array}{l}\text { Dr. Tor } \\
\text { Oiamo, } 2014 . \\
\text { Nitrogen } \\
\text { dioxide data } \\
\text { were indexed } \\
\text { to DMTI } \\
\text { Spatial Inc. } \\
\text { postal codes, } \\
\text { were provided } \\
\text { by CANUE }\end{array}$ \\
\hline
\end{tabular}




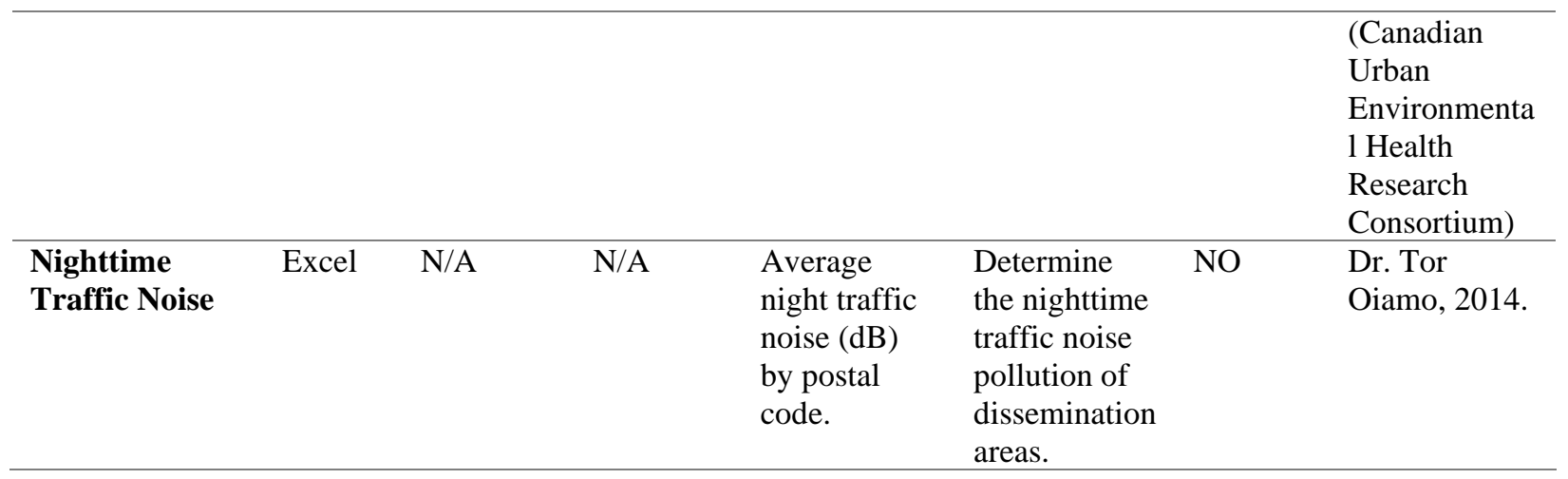

Prior to the analysis, the spatial files were imported into ArcGIS Pro and, they were projected into the WGS 84 coordinate system. The data were projected to one coordinate system, in order to ensure accurate and precise analysis. A geographic coordinate system was important in order to utilize meters as units of measurements in the study.

The non-spatial data, therefore, were joined to their respective spatial geographies - either dissemination areas or postal codes, in order to display the data spatially. For instance, the MSDI indices were joined to the dissemination area file; however, the nitrogen dioxide and noise pollution concentration data were joined to the postal code locations. The Join tool in ArcGIS Pro was employed in order to accomplish this. The chosen geography for this study is dissemination areas. Therefore, the data represented by postal codes were spatially joined into the DA level, usually the Spatial Join tool in ArcGIS. This included the air pollution and noise pollution datasets. The attributes were summarized by Average, Sum, Minimum, Maximum and Standard Deviation (SD). 


\subsection{Spatial Analysis}

GIS analysis methodology was used in order to calculate the accessibility to greenspace and the vulnerability to environmental exposures in ArcGIS software.

\subsubsection{Greenspace Accessibility}

Greenspace accessibility was calculated from the park shapefile for this analysis. Unlike the other environmental exposure data, greenspace accessibility was not acquired as a quantifiable metric and needed to be calculated. As previously stated, 1 hectare of greenspace is recommended within a 15-minute walk in order for optimal benefits (Evergreen, 2004). Firstly, the Select by Attribute tool was used in order to only select parks larger than or equal to 1 hectare for the analysis. Throughout Toronto there are 1332 green spaces larger than 1 hectare. This indicates that only approximately $40 \%$ of the parks in Toronto provide optimal health benefits to residents. For this analysis, 500 meters was determined as the optimal distance for greenspace accessibility to residents of Toronto (Natural England, 2010). Due to data accessibility and confidentiality, the centroid of the dissemination area was used to represent the population. A study by Jones et al., 2009 examined access to greenspace and effects of area deprivation by calculating the centroids of their study geography to identify greenspace accessibility. Therefore, the centroid was calculated, then buffered using the Buffer Tool in ArcGIS Pro, by 500 meters. The new buffered centroids were Clipped to the boundary of the city of Toronto for higher accuracy. Next, the parks selected for the analysis (larger or equal to $1 \mathrm{ha}$ ) were Clipped by the buffered centroids in order to display 'accessible' greenspace. This represents the areas of parks and public greenspace that are within 500 meters from the center of the dissemination areas. In order to display the accessible greenspace by dissemination area, the accessible greenspace shapefile and dissemination area shapefile were joined using the Union tool. Then, the parks were selected from the Attribute Table 
and a new layer was created. This was done in order for the accessible greenspace to be separated based on dissemination areas. Finally, the greenspace DA Union shapefile was dissolved by dissemination area. The final shapefile displayed the summed area of accessible greenspace within each dissemination area of Toronto.

\subsubsection{Vulnerability Assessment}

The map layers representing the environmental exposure were reclassified into categorical data, in order to be combined in the vulnerability assessment (Sahin \& Mohamed, 2014). Table 3.2.1 outlines the reclassification of the environmental exposure layers within the study. Reclassification is the process of changing the interpretation of data for analysis by taking input values and replacing them with new output values (ESRI, n.d.). For example, the nitrogen dioxide concentration value of $17.65 \mathrm{ppb}$ was reclassified as the value 30 . This was done in order to group the environmental exposures into quintile group categorical data. In ArcGIS, the range of the environmental exposure levels symbology was set to 5 quintile groups. An exception was that noise pollution data was manually regrouped into the reclassification categories. The World Health Organization (2018), recommends that road traffic be below $53 \mathrm{~dB}$, which is associated with adverse health effects. And more specifically, that noise levels produced by road traffic during the night time should be below $45 \mathrm{~dB}$ (World Health Organization, 2018). The classification reflects the possibility of adverse health effects associated with noise levels severely greater than recommended by the world health organization found within the data. The ranges of the reclassified variables were unequal; however, this was not a major limitation because the vulnerability calculation was then standardized.

The vulnerability reclassification of 50 represented a high vulnerability to the environmental exposures, and therefore associated negative health impacts (Choudhary et al., 
2018). The reclassification of 10 represented a low risk vulnerability to the health impacts associated with the environmental exposures. For instance, higher levels of nitrogen dioxide concentration were reclassified as 50 , representing higher vulnerability of the population to the environmental stressor. The accessible greenspace layer was an exception, as lower greenspace accessibility is associated with higher vulnerability Heckert, 2013). Therefore, the dissemination areas with lower accessible greenspace was reclassified as 50, representing higher vulnerability and fewer health benefits.

Table 3.4.1. Reclassification of the environmental exposure layers data

\begin{tabular}{|c|c|c|}
\hline Environmental Exposure Layers & Range & Vulnerability Reclass \\
\hline \multirow[t]{5}{*}{ Accessible Greenspace Cover } & 0.000 & 50 \\
\hline & $0.01-5.22$ & 40 \\
\hline & $5.22-11.53$ & 30 \\
\hline & $11.53-20.99$ & 20 \\
\hline & $20.99-80.11$ & 10 \\
\hline \multirow[t]{5}{*}{ Social Deprivation } & $-9999.00-1.00$ & 10 \\
\hline & $1.01-2.00$ & 20 \\
\hline & $2.01-3.00$ & 30 \\
\hline & $3.01-4.00$ & 40 \\
\hline & $4.01-5.00$ & 50 \\
\hline \multirow[t]{5}{*}{ Material Deprivation } & $-9999.00-1.00$ & 10 \\
\hline & $1.01-2.00$ & 20 \\
\hline & $2.01-3.00$ & 30 \\
\hline & $3.01-4.00$ & 40 \\
\hline & $4.01-5.00$ & 50 \\
\hline \multirow[t]{2}{*}{ Nitrogen Dioxide Concentration } & $0.00-15.93$ & 10 \\
\hline & $15.93-17.65$ & 20 \\
\hline
\end{tabular}




\begin{tabular}{lll}
\hline & $17.65-19.14$ & 30 \\
\cline { 2 - 3 } & $19.14-20.87$ & 40 \\
\cline { 2 - 3 } & $20.87-37.03$ & 50 \\
\hline Noise Pollution Levels & $0.00-55.00$ & 10 \\
\cline { 2 - 2 } & $55.01-65.00$ & 20 \\
\cline { 2 - 2 } & $65.01-75.00$ & 30 \\
\hline $75.01-78.00$ & 40 \\
& \\
\hline
\end{tabular}

The study Choudhary et al. (2018) utilized Equation 1 in order to successfully calculate the environmental vulnerability of their study site. This study integrated the same formula to calculate the vulnerability of Toronto dissemination areas to the environmental exposure variables: access to greenspace, noise pollution, air pollution and, social and material deprivation. Where [Theme $\mathrm{X}]$ represented the environmental exposure variable.

Equation 1:

$0.1 *[$ Theme 1]+0.1 $*[$ Theme 2] $+0.1 *[$ Theme 3] + 0.1*[Theme 4] + 0.1*[Theme 5]

The environmental exposure variables were combined. This was done by merging the attribute tables of the 5 exposure layers, creating a new field named "Total Vulnerability" and finally, calculating the field by using Equation 1. The vulnerability result was a function of the exposure (Choudhary, Boori \& Kupriyanov, 2018); where higher exposure insinuates a higher vulnerability to the associated negative health impacts. Higher values indicate a higher vulnerability and vice versa. The calculated index was then standardized into a range of 0 to 1 in order to take into consideration the different ranges of variables. 


\subsection{Statistical Analysis}

\subsubsection{Statistical Testing: $T$-Test and Chi-Square}

Prior to performing logistic regression, the variables were analyzed using independent samples t-testing and chi-square testing. The tests were used to evaluate the contribution of each dependent variable and to evaluate for significance. Independent t-testing was used to determine whether the means of two unrelated groups are different. In the case of this study, to determine if public housing and non-public housing were significantly different. The test utilized the continuous dependent variables and tested them against the categorical variables, housing or nonhousing. Furthermore, chi-square tests were used to test the relationships between the categorical variables. More specially, to test the null hypothesis that no relationship exists between the categorical variables in the population.

\subsubsection{Logistic Regression}

In order to explore how environmental exposures impacted housing neighbourhoods, a statistical approach was applied. Logistic regression was selected as opposed to linear regression because the dependent variables did not have a linear relationship with the independent variable, and the variables were also categorical. Logistic regression was run on the environmental exposure dataset to determine the best model in SPSS software. In logistic regression, the dependent variable is binary, therefore, it's coded as 1 (TRUE) or 0 (FALSE) (MedCalc, n.d.). The purpose of logistic regression is to analyze a dataset in which there are one or more independent variables that determine an outcome, the dichotomous variable. Logistic regression predicts the probability of an outcome given the set of predictor variables (Field, 2009). Logistic regression was used to analyze if environmental exposure variables determined the outcome of public housing. The environmental exposures used in the regression analysis as dependent predictors were: average nitrogen dioxide concentrations, average night traffic noise, average accessible greenspace, 
material deprivation and social deprivation. It is important to state that normality was assumed for the variables used. The predictor variables were set as categorical data, the first category was set as the indicator reference in the model. The categorical values were previously outlined in Table 3.4.1. The dichotomous dependent variable was dissemination areas with public housing developments (1) or dissemination areas with no public housing developments (0). However, this was problematic due to the significantly different number of dissemination areas with and without public housing. The large variation in the number of cases within the two groups can lead to poor classification, biases and failures in the model (Pallant, 2005). However, the overall sample population was very large producing a powerful statistical model despite the difference in sample sizes. The logistic function (Equation 2) gave the probability of public housing within the dissemination area as a function of the exposure variables (Bavaghar, 2015). The logistic function is as follows:

$$
\mathrm{P}=\mathrm{E}(\mathrm{Y})=\frac{\exp (\beta 0+\beta 1 X 1+\beta 2 X 2+\cdots+\beta i X i)}{1+\exp (\beta o+\beta 1 X 1+\beta 2 X 2+\cdots+\beta i X i)}
$$

where: $\mathrm{p}$ is the probability of public housing, $\mathrm{E}(\mathrm{Y})$ is the expected value of the binary dependent variable $(\mathrm{Y}), \beta \mathrm{o}$ is the constant to be estimated and $\beta \mathrm{i}$ is the predicted coefficient of each independent variable Xi (Bavaghar, 2015). The final result of logistic regression is a probability score $(\mathrm{P})$ that ranges between 0 and 1 , for each of the dissemination areas in Toronto. The $\mathrm{R}$ square was calculated, however in logistic regression $R^{2}$ is called pseudo $R^{2}$ as it indicates the fitness of the model but not the scatter of data around the fitted line (Bavaghar, 2015). The value of $\mathrm{R}^{2}$ is low in logistic regression, and should be between 0.2 and 0.4 , because of the binary response variable (Bavaghar, 2015). Furthermore, the statistical significance of the predictor variables was tested using the Wald chi-square and, the Hosmer-Lemeshow test was used for testing goodness 
of fit. It was also important to examine the outliers within the data, the points that do not fit well within the model, to deliver insights on dissemination areas and irregular environmental exposures levels. This methodology is innovative as, no studies within the current literature have used logistic regression models to predict the presence of public housing. However, many have used these methods to predict an outcome based on dependent predictor variables.

\subsection{RESULTS}

This section will present the findings from the spatial and statistic methods applied in this research.

\subsection{Public Housing Data}

Median household income has been displayed in Figure 4.1.1 The dissemination areas of high average income are depicted by blue and the dissemination areas of low income are depicted in red.

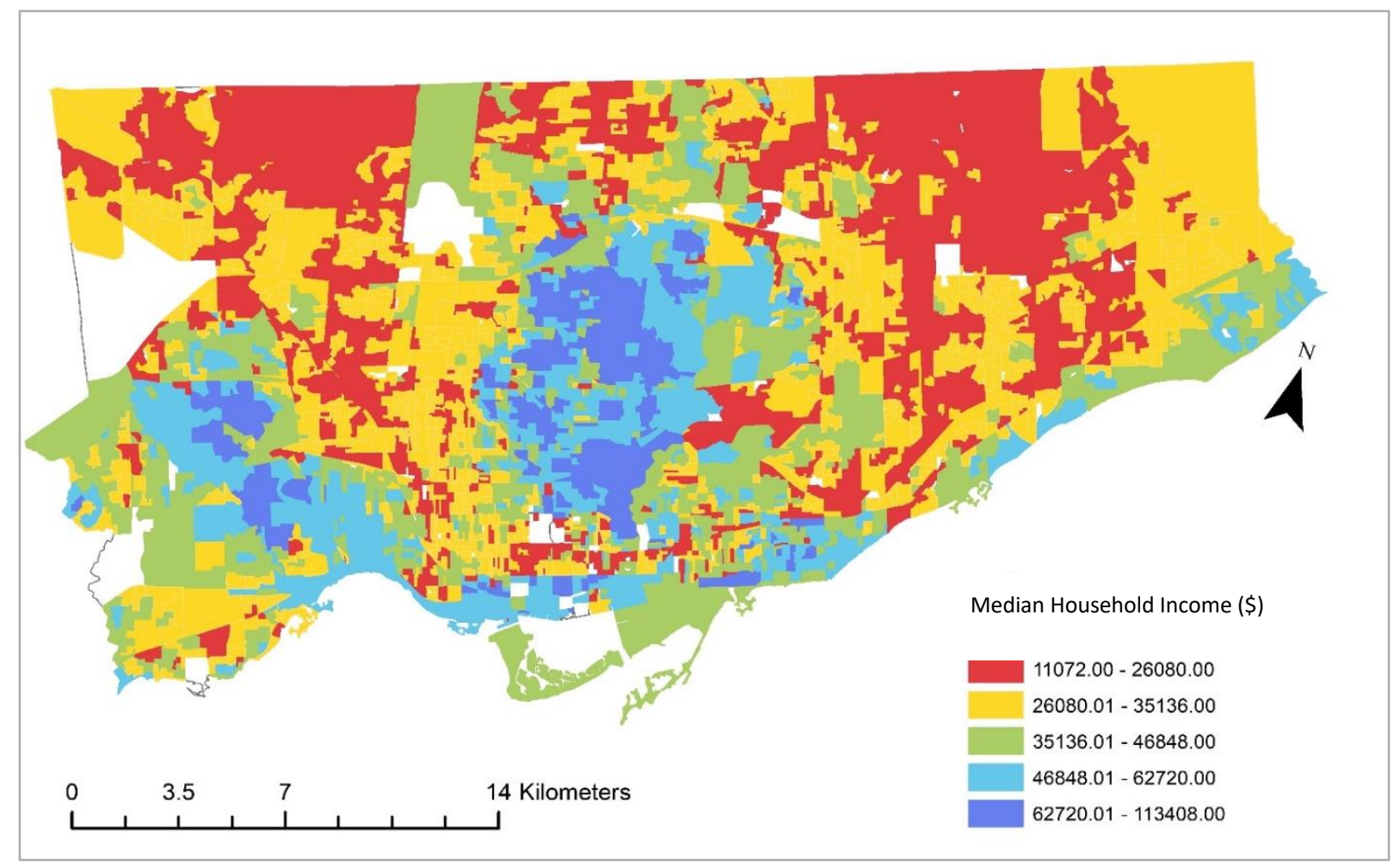

Figure 4.1.1 Median household income across Toronto dissemination areas, in dollars (\$). 
The majority of public housing developments are concentrated in the downtown core and northwestern areas of Toronto. The distribution of public housing follows similar trends to low income across Toronto (Tulk \& Grzincic, 2017; Statistics Canada, 2016). The number of public housing developments decrease within central uptown Toronto and are more concentrated in the lower income regions of Toronto.

Furthermore, the locations of public housing follow similar trends to areas with high visible minorities populations. Darker purple areas below in figure 4.1.2, signify higher concentrations of visible minorities, with public housing developments being concentrated in these areas.

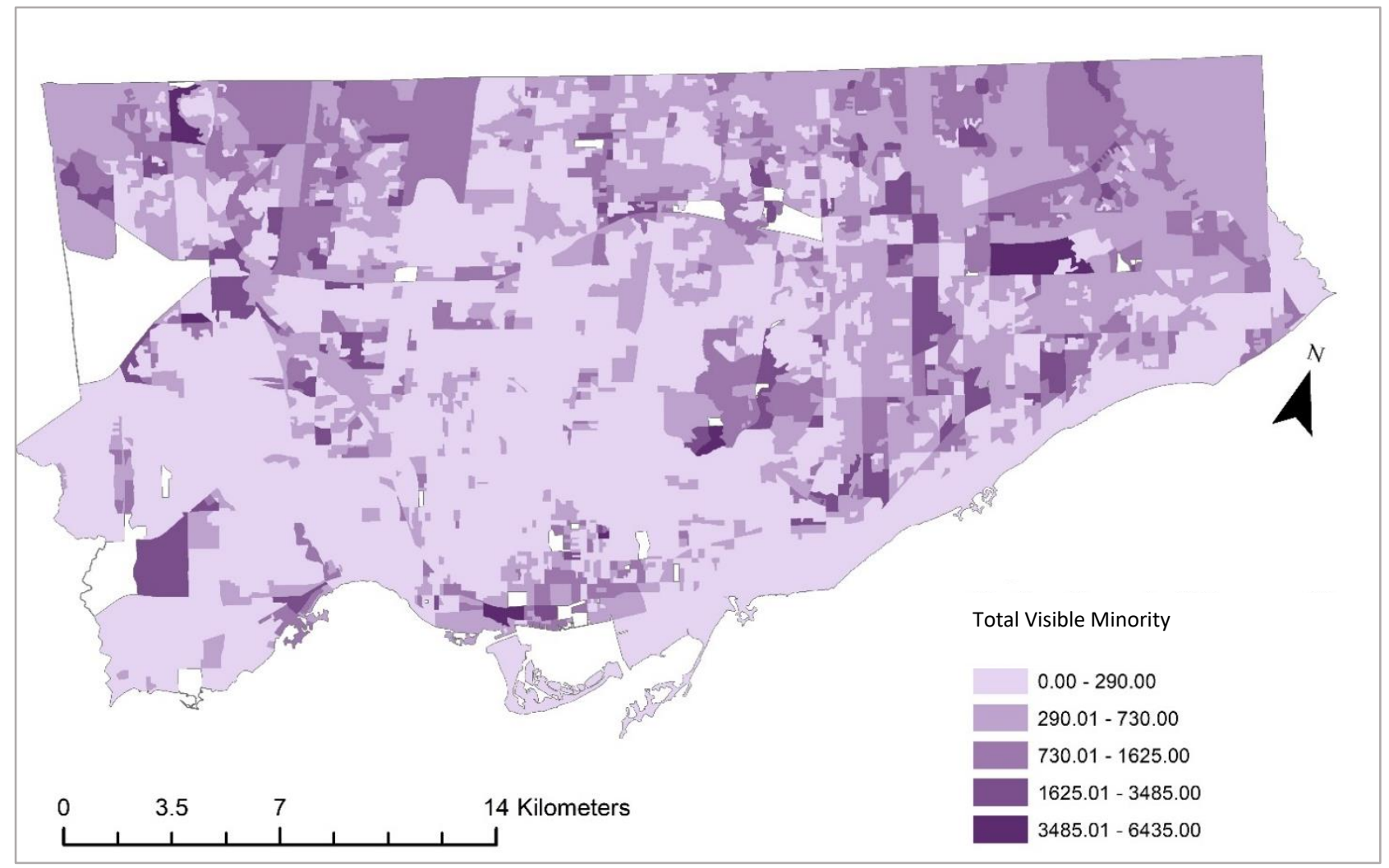

Figure 4.1.2 Total population of visible minorities (count) and the locations of public housing units, with more than 6 units, across the city of Toronto by dissemination area. Data source: City of Toronto, 2015; CHASS, 2016. 


\subsection{Environmental Exposure Data}

The nitrogen dioxide air pollution data acquired for this study were expressed in the units: parts per billion (ppb); however, most reports outline the recommended air pollution exposure levels as micrograms per cubic meter. The conversion factor for nitrogen dioxide is outlined in Equation 3 below:

$$
1 \mathrm{ppb}=1.88 \mu \mathrm{g} / \mathrm{m}^{3}
$$

where the atmospheric pressure of 1 atmosphere is assumed. The maximum concentrations of air pollution calculated for dissemination areas is presented in Figure 4.2.1.

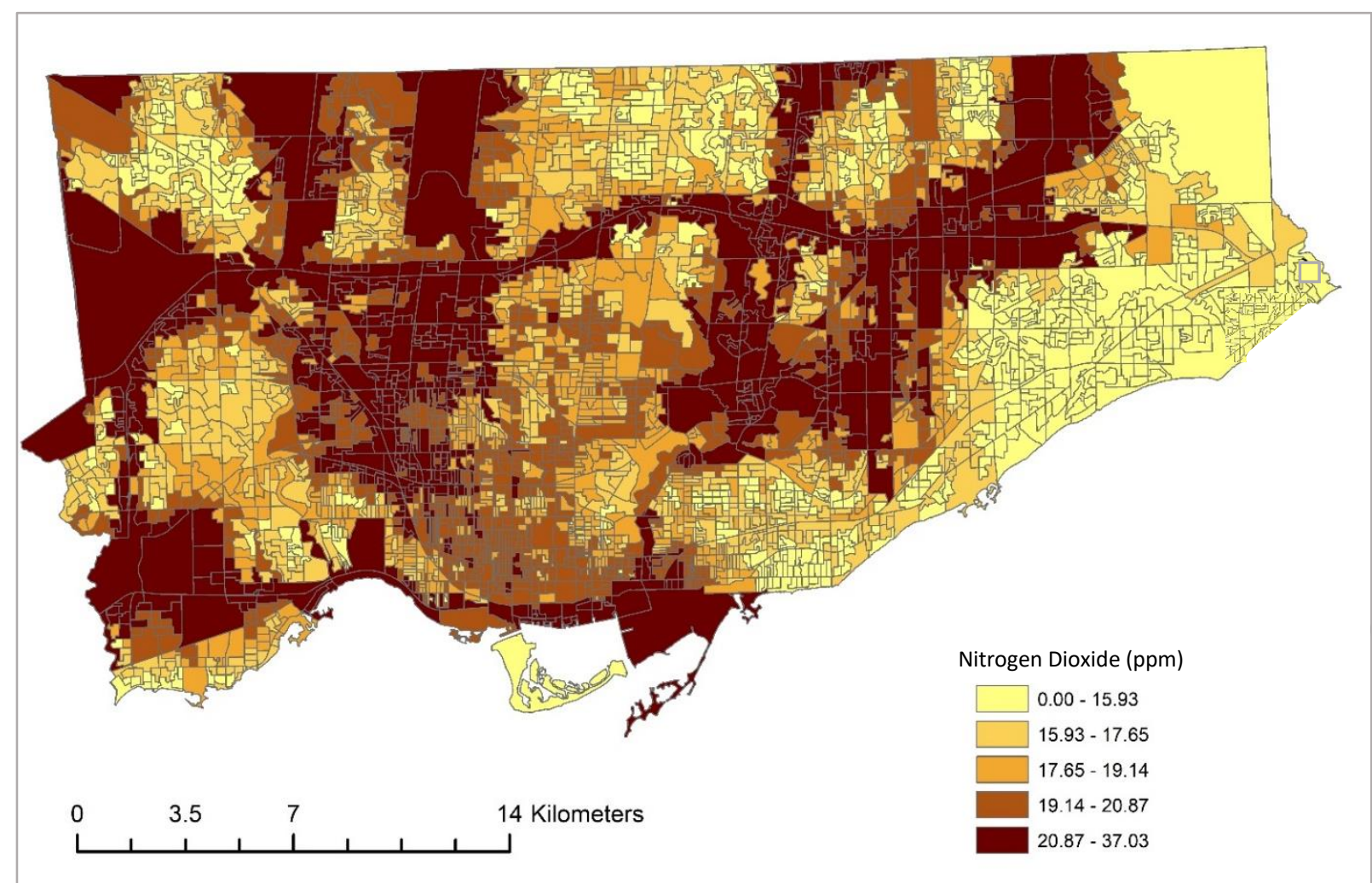

Figure 4.2.1 Maximum nitrogen dioxide estimates of the dissemination areas in parts per billion. Data Source: Dr Tor Oiamo, 2018 \& Toronto Open Data, 2016. 
The mean nitrogen dioxide concentration displayed in figure 4.2 .1 below is $18.418 \mathrm{ppb}$, which is equivalent to 34.625 micrograms per cubic meter of pollution. The maximum values estimated in Toronto exceed $35 \mathrm{ppb}$ (65.8 micrograms per cubic meter). The spatial pattern of the air pollution in Toronto follows major roadways. Liken to Figure 4.2.1, the concentration of nitrogen dioxide decreases within central uptown Toronto and increases within the downtown core and, towards the east and west.

Noise pollution measured at nightime hours (dBA) from traffic related sources was calculated for each dissemination area. Maximum values were assumed to encompass the exposure that individuals are exposed to throughout the dissemination areas, as previously stated. For example, if a high noise level value was calculated within the dissemination area, there is a high likelihood that those residing within the DA, could be exposed to that level. Nightime hours were defined as between 11:00 pm until 7:00 am (Toronto Public Health, 2017). The maximum value for each dissemination area shown in Figure 4.2.2, illustrates that higher values of A-weighted decibels levels ( $\mathrm{dBA}$ ) were measured around major highways within the GTA.

The maximum value estimated was $78 \mathrm{dBA}$, represented by the darker dissemination areas on the figure below. These dissemination areas are located on Highway 401, as well as where highways 401 and 427 converge. With the maximum noise estimates reaching $78 \mathrm{dBA}$, the average across Toronto is very high: $57.7 \mathrm{dBA}$ (for nightime levels). 


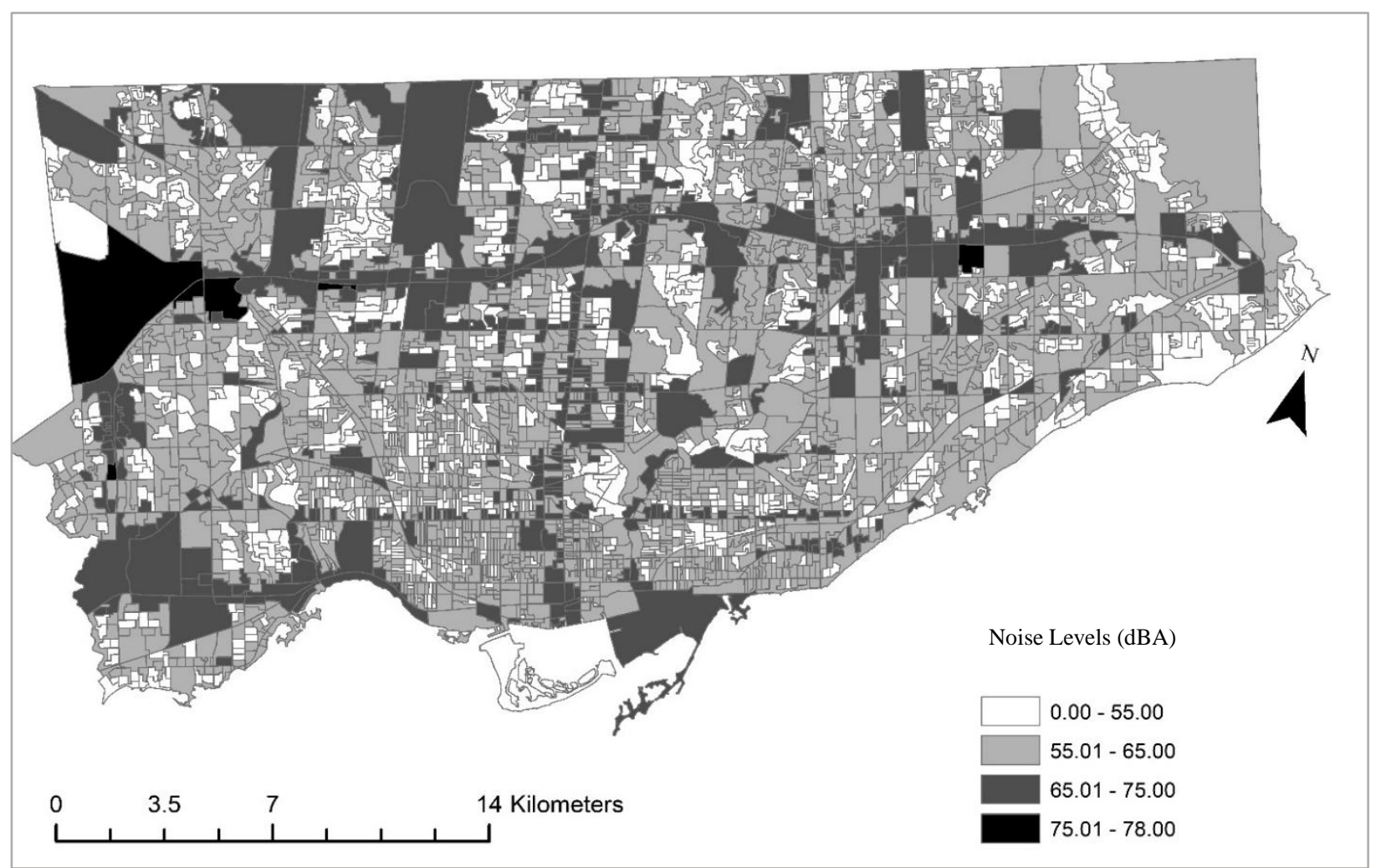

Figure 4.2.2 Maximum traffic related noise levels (dBA) for nighttime hours by dissemination areas in Toronto. Source: Dr Tor Oiamo, 2018.

The material and social deprivation indices were also displayed by dissemination area. The figures 4.2.3 and 4.2.4 display the factor score by quintiles for social deprivation and material deprivation, respectively. The social deprivation score in Toronto appears to not reflect major spatial patterns when examining the map visually. Contrastingly, the material deprivation of dissemination areas is correlated to income across Toronto. This is because the index calculation includes average household income. The central uptown areas of Toronto are subjected to less material deprivation than the outskirts of Toronto. There is a much more definitive pattern of material deprivation across Toronto than social deprivation. 


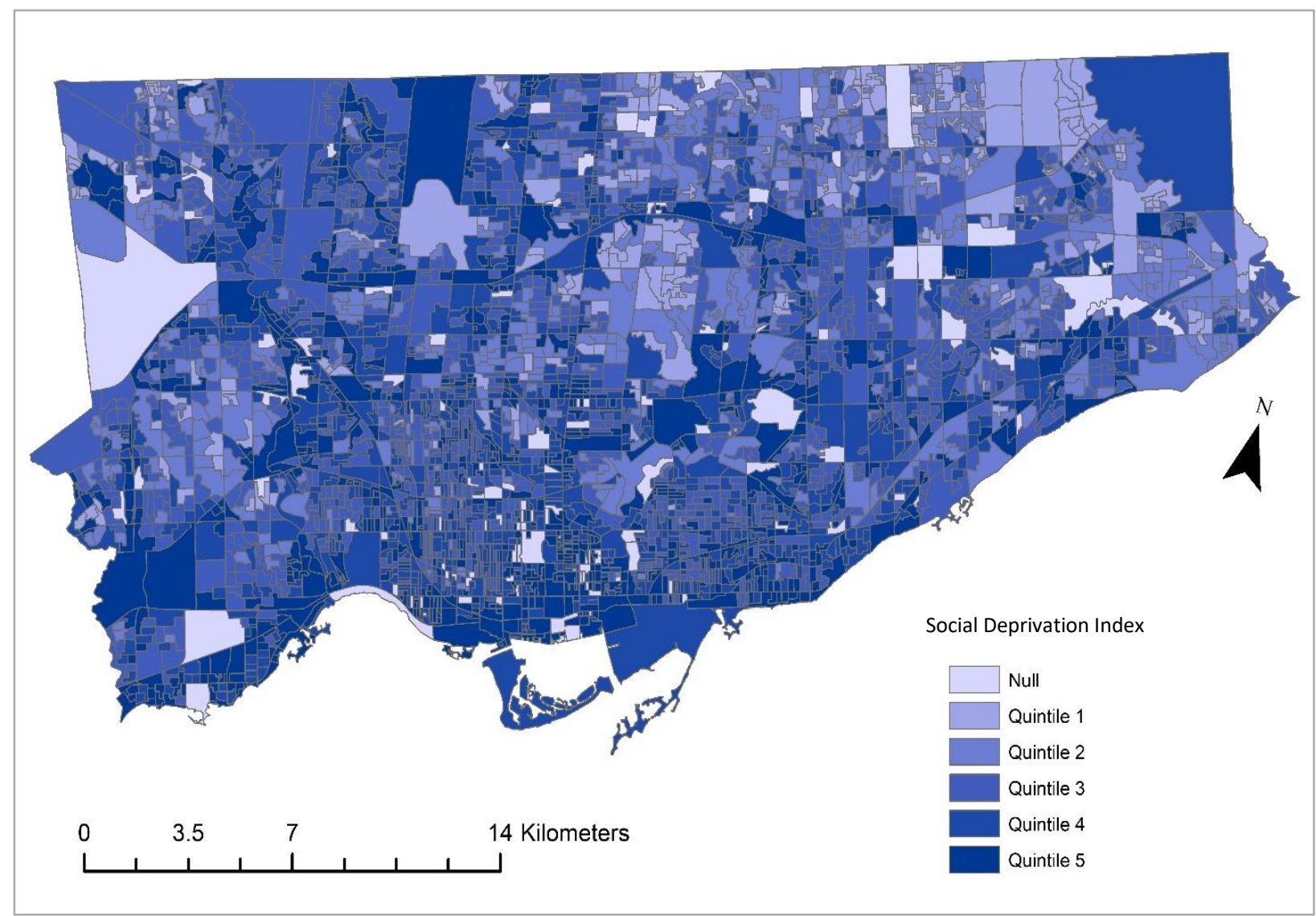

Figure 4.2.3 Social deprivation factor score by quintiles, where quintile 1 represents the least deprived and quintile 5 represents the most deprived. The factor scores displayed by dissemination areas in Toronto. Source: CANUE, 2018. 


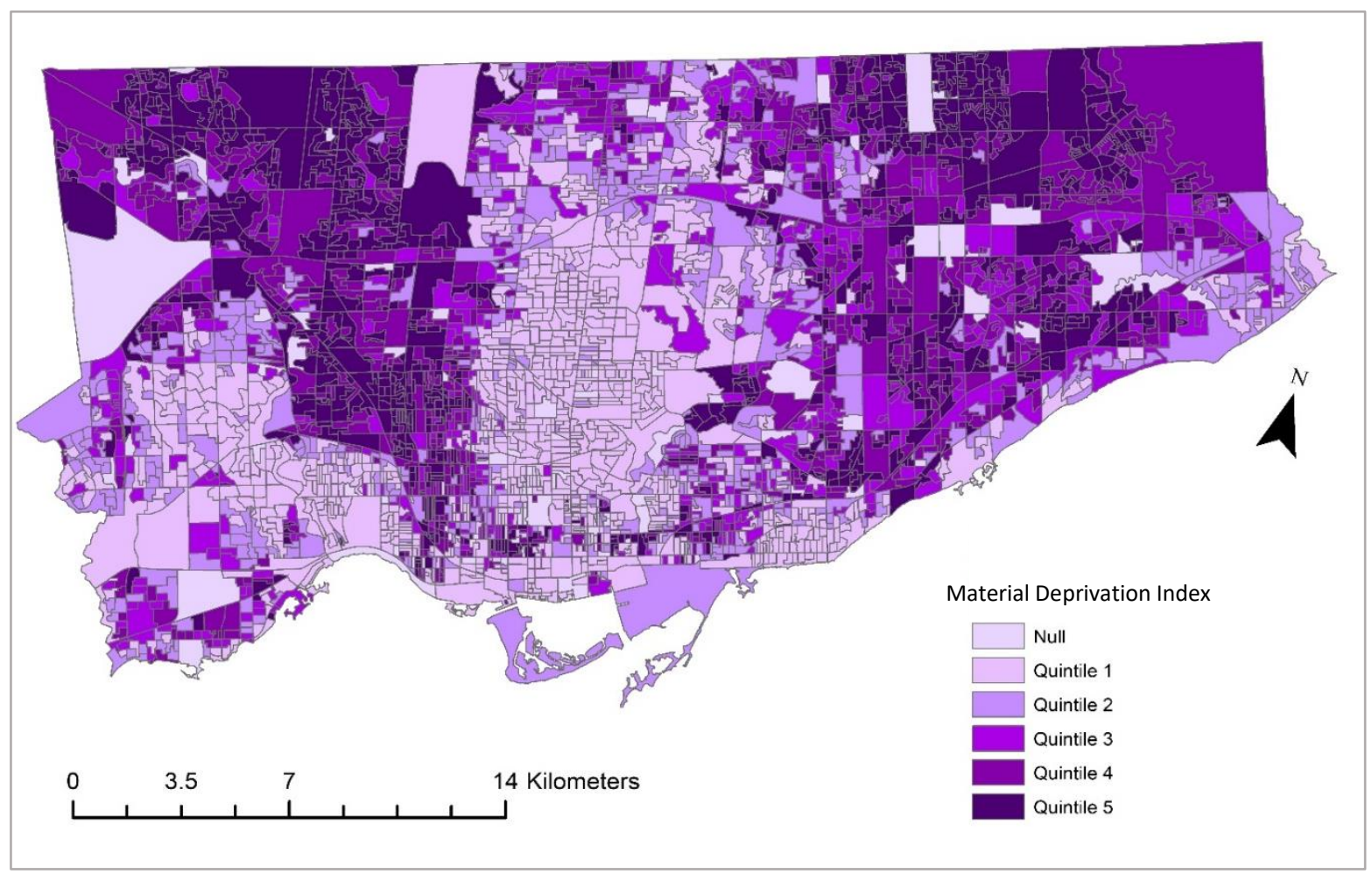

Figure 4.2.4 Material deprivation factor score by quintiles, where quintile 1 represents the least deprived and quintile 5 represents the most deprived. The factor scores displayed by dissemination areas in Toronto. Source: CANUE, 2018.

\subsection{Greenspace Accessibility}

Dissemination areas with low accessibility to greenspace are assumed to have lower access to the associated benefits. Accessibility was measured as percent cover of dissemination areas that are covered by the calculated accessible greenspace. The average cover of accessible parks throughout the dissemination areas was $4.53 \%$, with a minimum of $0.00 \%$ and a maximum of 80.11\%. The majority of high access is centralized in uptown Toronto, as well as in the east and west. The downtown core has very little to no access to greenspace. The majority of dissemination areas have very little to no access to greenspace defined by the methodology of this study. 


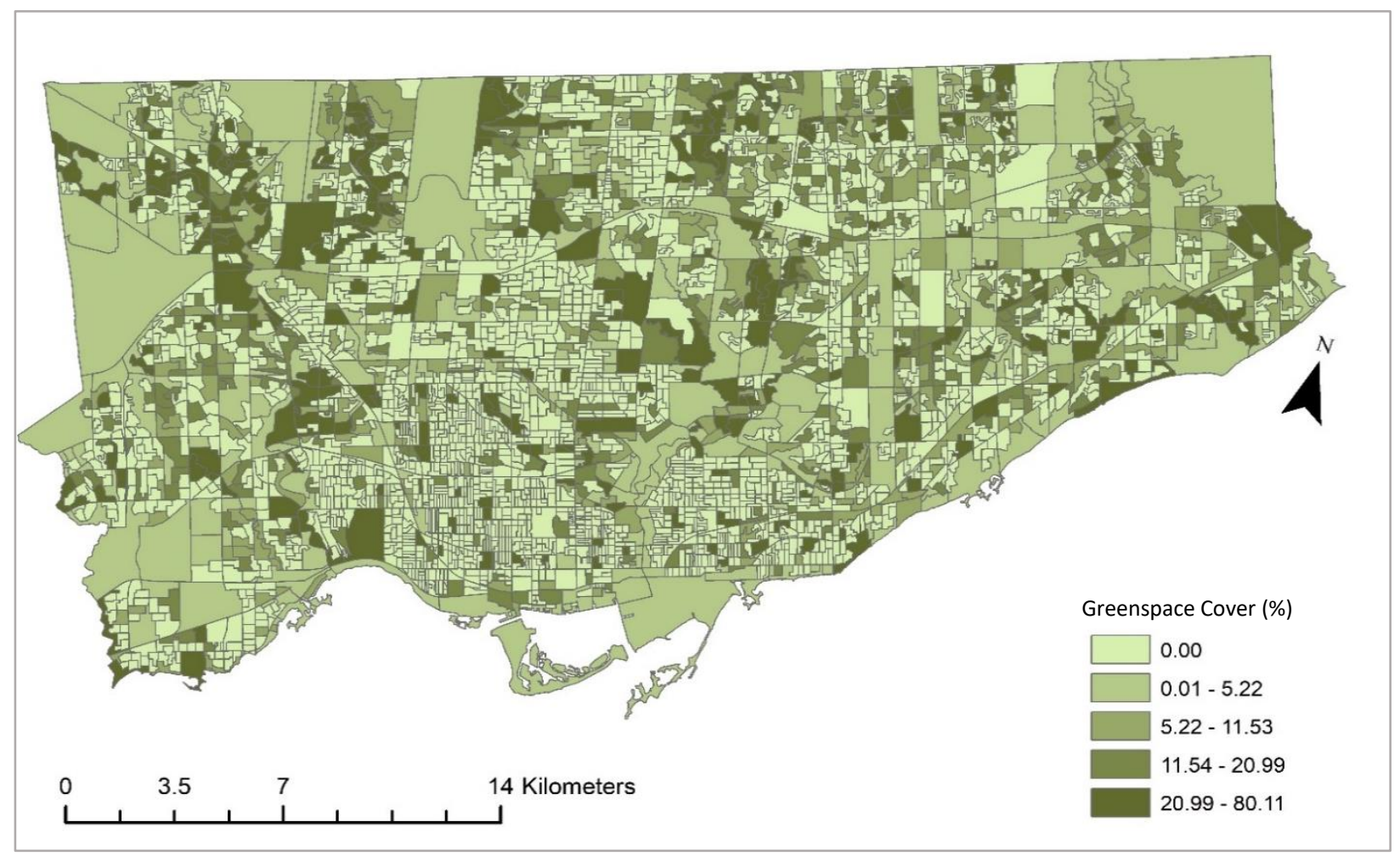

Figure 4.3.1 The total cover (\%) of accessible pubic greenspace by dissemination areas in Toronto, displayed by quintile. Data acquired from the city of Toronto open data catalogue on June, $7^{\text {th }}, 2019$.

\subsection{Vulnerability Assessment}

The calculated vulnerability for the city of Toronto by dissemination areas is shown in Figure 4.4.1. Vulnerability was calculated as a function of exposure and sensitivity to the environmental exposures in this analysis. These exposures were high air pollution (nitrogen dioxide concentration), high noise pollution levels (dBA), high social and material deprivation, and finally, low accessibility to the health benefits greenspaces. The vulnerability of dissemination areas was categorized into 5 classes: low, reasonable, moderate, high and extreme vulnerability. The vulnerability ranges are outlined in table 4.4 .1 below. 
Table 4.4.1 The vulnerability index range and associated vulnerability classes.

\begin{tabular}{ll}
\hline Vulnerability Index Range & Vulnerability \\
\hline $0.00-0.23$ & Low Vulnerability \\
\hline $0.23-0.38$ & Reasonable Vulnerability \\
\hline $0.38-0.52$ & Moderate Vulnerability \\
\hline $0.52-0.66$ & High Vulnerability \\
\hline $0.66-1.00$ & Extreme Vulnerability \\
\hline
\end{tabular}

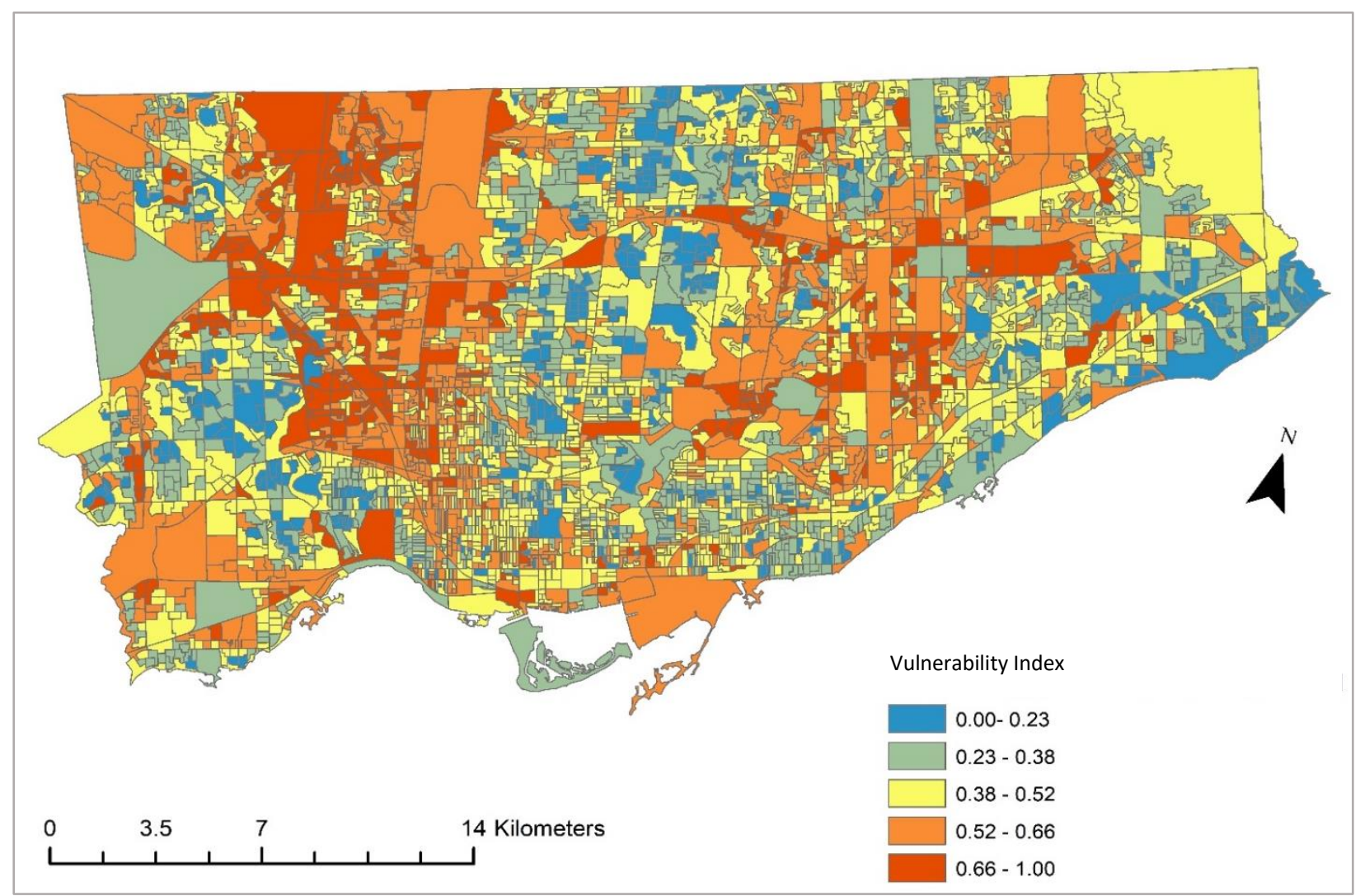

Figure 4.4.1 Vulnerability scores for environmental exposure to air pollution, noise pollution, lack of accessible greenspace, and material and social deprivation; across dissemination areas in Toronto. 


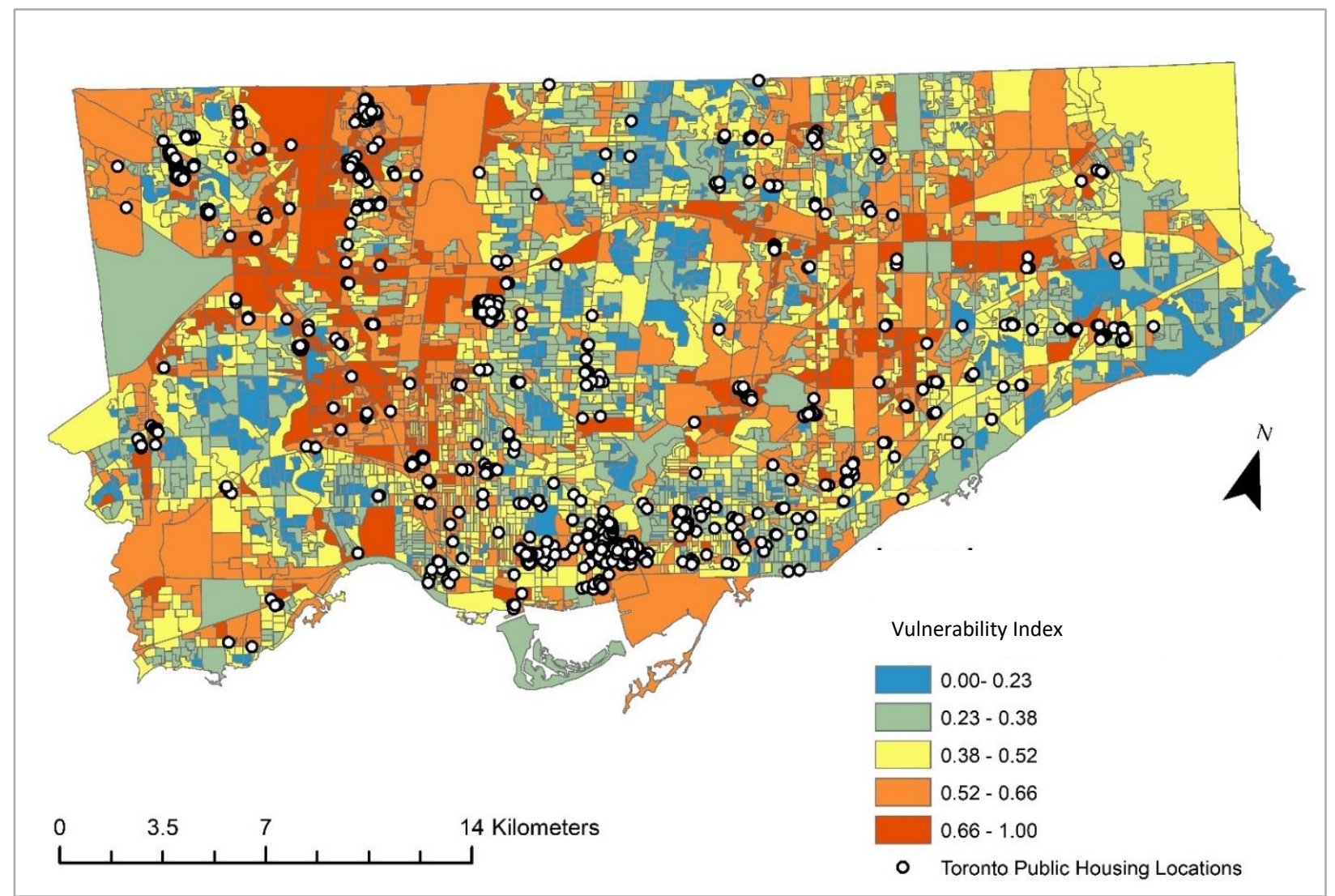

Figure 4.4.2 The location of public housing developments and the vulnerability of dissemination areas to the selected environmental exposures.

Overall, the dissemination areas that are extremely vulnerable to the environmental exposures are dispersed throughout the north western and eastern parts of Toronto. When examining figure 4.4.2 below, the areas of extreme and high vulnerability are within proximity to the public housing developments across Toronto. However, there are exceptions to this pattern. There appears to be some areas such as the downtown core, where public housing developments are within lower vulnerability areas. As well, there are high vulnerability dissemination areas where no public housing units exist. 


\subsection{Statistical Analysis: Descriptive \& Bivariate Results}

Descriptive analysis of the variables is reported below in Table 4.5.1. The sample size, mean, standard deviation and, minimum and maximum values were reported in order to describe the characteristics of the variables used in this analysis. The sample size for the variables were all 3685 , which indicates that the variables were correctly joined to the dissemination areas. There are 3685 dissemination areas across Toronto. The average nitrogen dioxide concentration was 18.71 ppb $(\mathrm{SD}=10.52)$, the average noise pollution was $58.48 \mathrm{dBA}(\mathrm{SD}=3.81)$, greenspace cover was $4.53 \%(\mathrm{SD}=10.52)$, and material and social deprivation averages were around $40(\mathrm{SD}=0.22$, $\mathrm{SD}=0.27)$, respectively.

Table 4.5.1. Descriptive analysis of environmental exposure variables: sample size, mean, standard deviation, minimum and maximum.

\begin{tabular}{lcclcc}
\hline Variables & $\mathbf{N}$ & Mean & $\begin{array}{l}\text { Standard } \\
\text { Deviation }\end{array}$ & Minimum & Maximum \\
\hline $\begin{array}{l}\text { Greenspace } \\
\text { Cover }\end{array}$ & 3685 & 4.53 & 10.52 & 0.00 & 80.11 \\
\hline $\begin{array}{l}\text { Nitrogen } \\
\text { Dioxide }\end{array}$ & 3685 & 18.71 & 3.81 & 0.00 & 37.04 \\
\hline Noise & 3685 & 58.48 & 7.98 & 0.00 & 78.00 \\
\hline $\begin{array}{l}\text { Material } \\
\text { Deprivation }\end{array}$ & 3685 & 42.97 & 0.22 & 10 & 60 \\
\hline $\begin{array}{l}\text { Social } \\
\text { Deprivation }\end{array}$ & 3685 & 39.12 & 0.27 & 20 & 60 \\
\hline
\end{tabular}

The box plot below displays the distribution of values of each exposure variable used within the analysis. The box plot shows that the distribution of the variables is very different, with the exception of the social and material deprivation scores. The distribution is identical because the data was acquired as quantile groups, not raw data. Furthermore, the distribution of greenspace accessibility, air pollution and noise levels are very different. Examining the noise pollution, the median is much higher than the other variables. When examining the figure below, only $25 \%$ of the noise levels are below approximately $54 \mathrm{dBA}$. Contrastingly, it appears that the median levels 
of air pollution and greenspace are lower. When examining the air pollution box plot, there is a strong agreement between air pollution levels across the city of Toronto. Finally, the greenspace accessibility levels are very low across Toronto. According to the figure below, $75 \%$ of the dissemination areas have an appropriate greenspace accessibility of around $3 \%$.

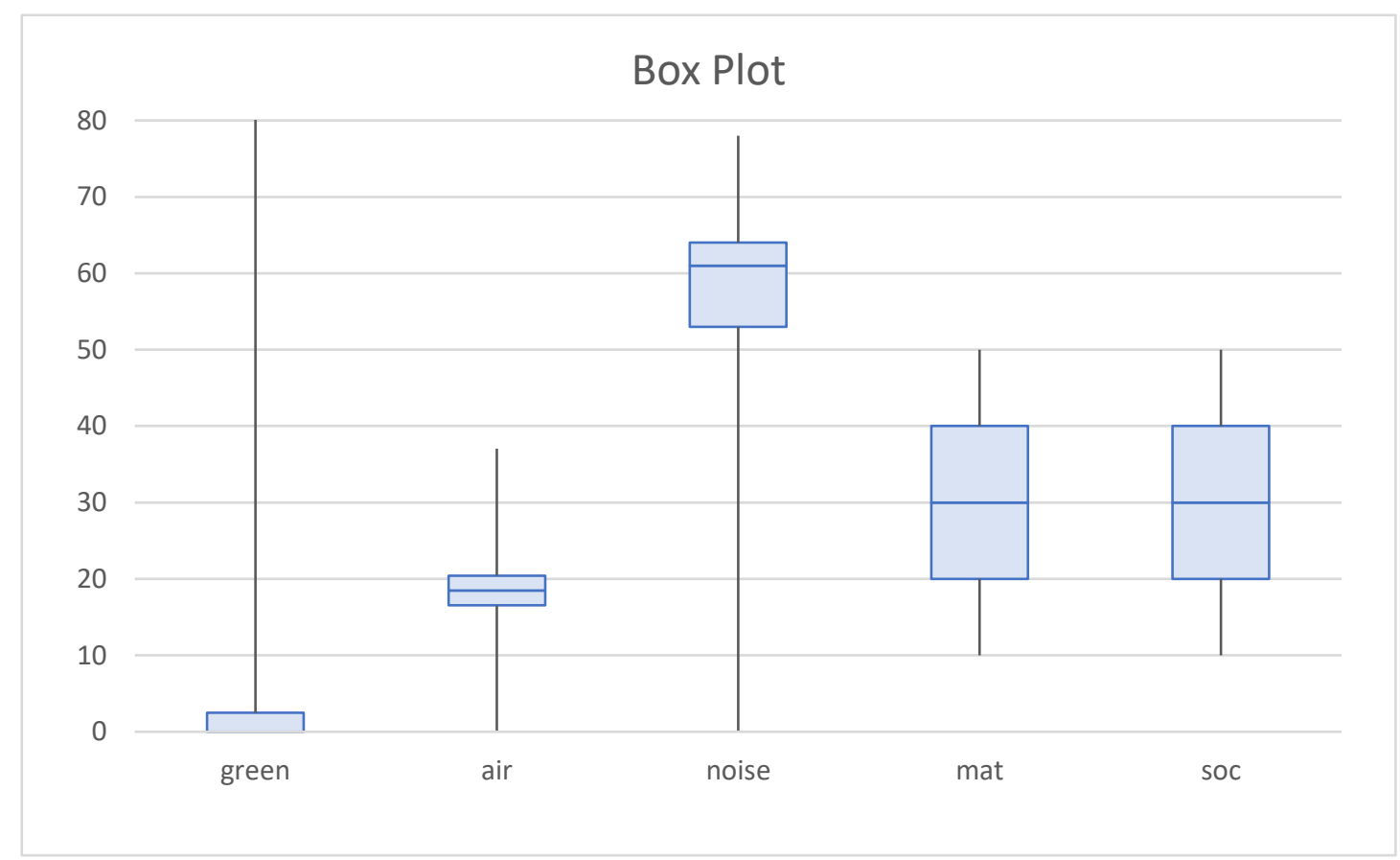

Figure 4.5.1. Box plot displaying the distribution characteristics of the exposure variables used in this analysis.

An independent samples t-test was conducted to compare nitrogen dioxide concentrations, greenspace cover and noise levels in public housing and non-public housing dissemination areas. The t-test was employed in order to determine if there's a significance difference $(\mathrm{p}<0.05)$ between the means of the two groups: public housing and non-public housing dissemination areas, for each variable. When examining nitrogen dioxide concentration within the city of Toronto. There was a significant difference in the scores for public housing $(M=19.29, \mathrm{SD}=3.63)$ and nonpublic housing conditions $(18.652, \mathrm{SD}=3.83) ; \mathrm{t}(3683)=-2.88, \mathrm{p}=0.004$. Therefore, this suggests that higher air pollution does occur within dissemination areas with public housing present. 
Similarly, noise pollution showed highly significant differences in the scores for public housing $(\mathrm{M}=60.47, \mathrm{SD}=7.376)$ and non-public housing $(\mathrm{M}=58.30, \mathrm{SD}=8.012)$ conditions, $\mathrm{t}(3683)=-$ 4.668, $\mathrm{p}=0.000$. This significant relationship between noise and dissemination areas indicates that public housing developments are exposed to higher noise levels than areas without public housing. Contrastingly, there was no significant relationship between greenspace cover and, public housing $(\mathrm{M}=5.286, \mathrm{SD}=11.147)$ and non-public housing $(\mathrm{M}=4.457, \mathrm{SD}=10.463)$ conditions; $\mathrm{t}(3683)=-$ $1.347, \mathrm{p}=0.178$. This is most likely because within urban landscapes greenspaces that are more than 1ha are scarce, because of the high building and population density. These statistics are reported in Table 4.2.2 and 4.2.3 below, showing the group statistics and independent t-tests.

Table 4.5.2 Independent Samples T-Test

\begin{tabular}{|c|c|c|c|c|c|c|}
\hline Variables & $\mathbf{F}$ & Sig & $\mathbf{T}$ & Df & Sig (2-tailed) & Mean Diff \\
\hline Nitrogen Dioxide & 0.87 & 0.350 & & & & \\
\hline Equal Variances assumed & & & -2.88 & 3683 & 0.0040 & -2.17 \\
\hline $\begin{array}{l}\text { Equal variances not } \\
\text { assumed }\end{array}$ & & & -3.01 & 394.13 & 0.0030 & -2.17 \\
\hline Greenspace Cover & 4.18 & 0.041 & & & & \\
\hline Equal Variances assumed & & & -1.35 & 3683 & 0.18 & -0.83 \\
\hline $\begin{array}{l}\text { Equal variances not } \\
\text { assumed }\end{array}$ & & & -1.28 & 374.44 & 0.20 & -0.83 \\
\hline Noise & 21.16 & 0.000 & & & & \\
\hline Equal Variances assumed & & & -4.67 & 3683 & 0.00 & -0.64 \\
\hline $\begin{array}{l}\text { Equal variances not } \\
\text { assumed }\end{array}$ & & & -4.99 & 389.69 & 0.00 & -0.64 \\
\hline
\end{tabular}

Table 4.5.3. Group Statistics

\begin{tabular}{lllll}
\hline Variables & Binary & $\mathbf{N}$ & Mean & Std Deviation \\
\hline Nitrogen Dioxide & 0 & 3365 & 18.65 & 3.83 \\
\cline { 2 - 5 } & 1 & 320 & 19.29 & 3.63 \\
\hline Greenspace Cover & 0 & 3365 & 4.46 & 10.46 \\
\cline { 2 - 5 } & 1 & 320 & 5.29 & 11.15 \\
\hline Noise & 0 & 3365 & 58.30 & 8.01 \\
\cline { 2 - 5 } & 1 & 320 & 60.47 & 7.38
\end{tabular}

A chi-square test was used to examine the relationship between the categorical environmental exposure data and public housing. The null hypothesis assumes there is no 
relationship on categorical variables, they are independent. The test of independence compares the observed pattern from the expected values if the variables were truly independent of each other.

Table 4.5.4 Processing Summary for the Chi-Square test on categorical independent variables.

\begin{tabular}{lllllll}
\hline & Valid & & Missing & & Total \\
\hline Variables & $\mathrm{N}$ & Percent & $\mathrm{N}$ & Percent & $\mathrm{N}$ & Percent \\
\hline $\begin{array}{l}\text { Housing } \\
\text { Greenspace } \\
\text { Cover }\end{array}$ & 3685 & $100 \%$ & 0 & $0.0 \%$ & 3685 & $100 \%$ \\
\hline $\begin{array}{l}\text { Housing } \\
\begin{array}{l}\text { Social } \\
\text { Deprivation }\end{array}\end{array}$ & 3685 & $100 \%$ & 0 & & & \\
\hline $\begin{array}{l}\text { Housing } * \\
\text { Material } \\
\text { Deprivation }\end{array}$ & 3685 & $100 \%$ & 0 & $0.0 \%$ & 3685 & $100 \%$ \\
\hline
\end{tabular}

Table 4.5.4 above, confirms that all dissemination areas are included within the categories within these variables. The variables greenspace cover, material and social deprivation were analyzed using chi-square testing because of their categorical nature. The greenspace cover was categorized within this analysis because a higher value of greenspace cover has a positive effect on the dissemination area, in other words, the environmental exposure is less. This is the opposite of the other environmental exposure variables, where a higher value indicates more environmental exposure, and negative impacts. Additionally, material and social deprivation were acquired as quintile classes, therefore there is no 'raw' data to analyze. The chi square results for the variables are outlined within the Tables 4.5.5 (a) \& (b), 4.5.6 (a) \& (b), as well as, 4.5.7 (a) \& (b).

Table 4.5.5. (a) Crosstabulation of housing and greenspace cover.

\begin{tabular}{|c|c|c|c|c|c|c|c|c|}
\hline & & & 10 & 20 & 30 & 40 & 50 & Total \\
\hline \multirow{8}{*}{ Housing } & \multirow[t]{4}{*}{$\mathbf{0}$} & Count & 2391 & 243 & 253 & 236 & 242 & \multirow{4}{*}{$\begin{array}{l}3365 \\
3365\end{array}$} \\
\hline & & Expected Count & 2380.60 & 246.60 & 246.60 & 246.60 & 246.60 & \\
\hline & & Residual & 10.40 & -12.60 & 13.60 & -10.60 & -4.60 & \\
\hline & & $\%$ of Total & $64.90 \%$ & $6.60 \%$ & $6.90 \%$ & $6.40 \%$ & $6.40 \%$ & \\
\hline & \multirow[t]{4}{*}{1} & Count & 216 & 27 & 17 & 32 & 28 & \multirow{4}{*}{$\begin{array}{l}320 \\
320\end{array}$} \\
\hline & & Expected Count & 226.40 & 23.40 & 23.40 & 23.40 & 23.40 & \\
\hline & & Residual & 8.60 & -0.40 & -10.40 & 12.60 & -10.40 & \\
\hline & & $\%$ of Total & $5.90 \%$ & $0.70 \%$ & $0.50 \%$ & $0.90 \%$ & $0.80 \%$ & \\
\hline
\end{tabular}




\begin{tabular}{lllllll|l|l|}
\hline Total & Count & 2607 & 270 & 270 & 268 & 270 & Total \\
& Expected & 2607 & 270 & 270 & 270 & 270 & $\begin{array}{l}\text { Count } \\
3685\end{array}$ \\
& & & & & & &
\end{tabular}

(b) Chi-square test of housing and greenspace cover.

\begin{tabular}{llll}
\hline & Value & DF & $\begin{array}{l}\text { Asymptomatic } \\
\text { Significance (2-sided) }\end{array}$ \\
\hline Pearson Chi-Square & 7.61 & 4 & 0.11 \\
\hline Likelihood Ratio & 7.38 & 4 & 0.12 \\
\hline $\begin{array}{l}\text { Linear by Linear } \\
\text { Association }\end{array}$ & 2.54 & 1 & 0.11 \\
\hline N of Valid Cases & 3685 & & \\
\hline
\end{tabular}

4.5.6 (a) Crosstabulation of housing and social deprivation

\begin{tabular}{|c|c|c|c|c|c|c|c|c|}
\hline & & & 10 & 20 & 30 & 40 & 50 & Total \\
\hline \multirow{4}{*}{ Housing } & $\mathbf{0}$ & Count & 383 & 537 & 954 & 895 & 596 & 3365 \\
\hline & & Expected Count & 365.30 & 497.70 & 891.20 & 892.20 & 718.70 & 3365 \\
\hline & 1 & Count & 17 & 8 & 22 & 82 & 191 & 320 \\
\hline & & Expected Count & 34.70 & 47.30 & 84.80 & 84.80 & 68.30 & 320 \\
\hline \multirow[t]{2}{*}{ Total } & & Count & 400 & 545 & 976 & 977 & 787 & Total \\
\hline & & Expected & 400 & 545 & 976 & 977 & 787 & $\begin{array}{l}\text { Count } \\
3685\end{array}$ \\
\hline
\end{tabular}

(b) Chi-square test of housing and greenspace cover.

\begin{tabular}{llll}
\hline & Value & DF & $\begin{array}{l}\text { Asymptomatic } \\
\text { Significance (2-sided) }\end{array}$ \\
\hline Pearson Chi-Square & 337.77 & 4 & 0.00 \\
\hline Likelihood Ratio & 305.38 & 4 & 0.00 \\
\hline $\begin{array}{l}\text { Linear by Linear } \\
\text { Association }\end{array}$ & 216.00 & 1 & 0.00 \\
\hline N of Valid Cases & 3685 & & \\
\hline
\end{tabular}

4.5.7 (a) Crosstabulation of housing and material deprivation

\begin{tabular}{|c|c|c|c|c|c|c|c|c|}
\hline & & & 10 & 20 & 30 & 40 & 50 & Total \\
\hline \multirow[t]{4}{*}{ Housing } & $\mathbf{0}$ & Count & 991 & 519 & 491 & 635 & 729 & 3365 \\
\hline & & Expected Count & 965.20 & 497.70 & 471.20 & 614.60 & 816.40 & 3365 \\
\hline & 1 & Count & 66 & 26 & 25 & 38 & 165 & 320 \\
\hline & & Expected Count & 91.80 & 47.30 & 44.80 & 58.40 & 77.60 & 320 \\
\hline \multirow[t]{2}{*}{ Total } & & Count & 1057 & 545 & 516 & 673 & 894 & Total \\
\hline & & Expected & 1057 & 545 & 516 & 673 & 894 & $\begin{array}{l}\text { Count } \\
3685\end{array}$ \\
\hline
\end{tabular}


(b) Chi-square test of housing and material deprivation.

\begin{tabular}{llll}
\hline & Value & DF & $\begin{array}{l}\text { Asymptomatic } \\
\text { Significance (2-sided) }\end{array}$ \\
\hline Pearson Chi-Square & 143.55 & 4 & 0.00 \\
\hline Likelihood Ratio & 125.00 & 4 & 0.00 \\
\hline $\begin{array}{l}\text { Linear by Linear } \\
\text { Association }\end{array}$ & 72.22 & 1 & 0.00 \\
\hline N of Valid Cases & 3685 & & \\
\hline
\end{tabular}

For the greenspace cover variable, there is no association between the presence of public housing and greenspace cover. The p-value indicates that these variables are independent of each other, and that there is no statistically significant relationship between the categorical variables $\left(\mathrm{X}^{2}(4, \mathrm{~N}=3685)=7.61, \mathrm{p}=0.11\right)$. Therefore, the presence of public housing does not significantly affect the cover of accessible greenspace. However, the presence of public housing significantly affects the presence of material deprivation, $\left(\mathrm{X}^{2}(5, \mathrm{~N}=3685)=153.03, \mathrm{p}=0.000\right)$ and social deprivation $\left(\mathrm{X}^{2}(5, \mathrm{~N}=3685)=356.58, \mathrm{p}=0.000\right)$. There is a statistical relationship between these categorical variables and public housing.

\subsection{Statistical Analysis: Logistic Regression}

A logistic model provides a better fit to the data if it demonstrates an improvement over the null model within the analysis (Peng, Lee \& Ingersoll, 2000). The predictor variables for this analysis were categorized during vulnerability analysis, and therefore were categorized for the logistic regression analysis (Table 4.6.1). The first variable was indicated as the reference for the analysis. A possible limitation of the analysis is the unbalanced sample size between the binary variable groups public housing dissemination areas and non-public housing dissemination areas in the logistic regression. However, this is not a fatal flaw to the overall study, as the total population size $(\mathrm{N}=3385)$ in the model displays a strong power of statistical significance. 


\begin{tabular}{lll}
\multicolumn{4}{l}{4.6 .1 Categorical variable coding for the predictor variables. } \\
\hline Variable Category & Frequency & Range of Variable \\
\hline Social Deprivation & 396 & $-9999.00-1.00$ \\
$\mathbf{1 0}$ & 545 & $1.01-2.00$ \\
$\mathbf{2 0}$ & 976 & $2.01-3.00$ \\
$\mathbf{3 0}$ & 980 & $3.01-4.00$ \\
$\mathbf{4 0}$ & 788 & $4.01-5.00$ \\
$\mathbf{5 0}$ & & \\
\hline Material Deprivation & 1057 & $-9999.00-1.00$ \\
$\mathbf{1 0}$ & 545 & $1.01-2.00$ \\
$\mathbf{2 0}$ & 516 & $2.01-3.00$ \\
$\mathbf{3 0}$ & 673 & $3.01-4.00$ \\
$\mathbf{4 0}$ & 894 & $4.01-5.00$ \\
$\mathbf{5 0}$ & & \\
\hline Greenspace Cover & 2607 & 0.00 \\
$\mathbf{1 0}$ & 270 & $0.01-5.22$ \\
$\mathbf{2 0}$ & 270 & $5.22-11.54$ \\
$\mathbf{3 0}$ & 268 & $11.54-20.99$ \\
$\mathbf{4 0}$ & 270 & $20.99-80.11$ \\
$\mathbf{5 0}$ & & \\
\hline Nitrogen Dioxide & 692 & $0.00-15.93$ \\
$\mathbf{1 0}$ & 753 & $15.93-17.65$ \\
$\mathbf{2 0}$ & 747 & $17.65-19.14$ \\
$\mathbf{3 0}$ & 747 & $19.14-20.88$ \\
$\mathbf{4 0}$ & 746 & $20.88-37.04$ \\
$\mathbf{5 0}$ & & \\
\hline Noise & 1138 & $0.00-55.00$ \\
$\mathbf{1 0}$ & 2067 & $55.01-65.00$ \\
$\mathbf{2 0}$ & 474 & $65.01-75.00$ \\
$\mathbf{3 0}$ & 6 & $75.01-78.00$ \\
$\mathbf{4 0}$ & & \\
\hline
\end{tabular}

The logistic regression analysis results are outlined in Table 4.6.2 below. The logistic model was fitted to the data to test the research hypothesis regarding the relationship between public housing locations and exposure variables. The logistic model provides a better fit of the data than the null model according to the table 4.6.2; the omnibus model test shows that the model was more effective than the null $(\mathrm{p}=0.00)$. The statistical significance of individual regression coefficients was tested using the Wald's chi-square statistic (Table 4.6.2). First, lower nitrogen dioxide levels categories were insignificant predictors of public housing locations $(\mathrm{p}>0.05)$. Overall, nitrogen dioxide was an insignificant predictor of public housing $(\mathrm{p}=0.10)$. However, category 50 representing the higher levels of nitrogen dioxide levels was a significant predictor of 
public housing locations $(\mathrm{p}<0.05)$. Overall, the accessible greenspace cover categories were found to not be a significant predictor, $\mathrm{p}>0.05$. This is most likely due to the very low amount of dissemination areas with accessible greenspace (Figure 4.5.1). But the odds ratio calculated for greenspace cover indicated that public housing presence is more likely to occur within areas of less greenspace cover. Next, within the social deprivation index predictor, categories $30,40,50$ and 60 were found to be significant predictors of public housing locations in Toronto $(\mathrm{p}<0.05)$. However, category 2 was not significant $(\mathrm{p}>0.05)$. High levels of social deprivation were significant predictors of public housing presence and overall, the model reports social deprivation as a significant predictor. The odds ratio indicates there is a large likelihood that socially deprived areas have public housing present. Furthermore, material deprivation was not a significant predictor of public housing throughout all categories in the model ( $\mathrm{p}>0.05)$. But, the higher levels of material deprivation were significant, as well as the variable was overall significant $(\mathrm{p}<0.05)$. Similarly, the materially deprived areas were more likely to contain public housing units than less deprived areas. Finally, within the noise level predictor variable, lower levels were significant predictors of public housing $(\mathrm{p}<0.05)$; however, the highest noise level category was not significant $(p>0.05)$. However, the noise pollution variable was a significant predictor $(p<0.05)$. The odds ratio indicates that higher levels of noise pollution suggest a high likelihood of public housing presence. Within table 4.6.2, the test of the y intercept (Constant*) was included in the analysis. The intercept is the expected mean value of public housing, when all predictor variables are equal to 0 . The Constant variable is significant $(\mathrm{p}<0.05)$, therefore it is not suggested that an alternative model be applied. 
Table 4.6.2 Logistic Regression Analysis of Public Housing Presence.

$\begin{array}{lllllll}\begin{array}{l}\text { Independent } \\ \text { Variables }\end{array} & \beta & \text { SE } \beta & \text { Wald's } X^{2} & \text { DF } & \text { Significance } & \begin{array}{l}\text { Odds } \\ \text { Ratio }\end{array}\end{array}$

Variables

\begin{tabular}{|c|c|c|c|c|c|c|}
\hline Nitrogen Dioxide & & & & & & \\
\hline Category 10 & & & 7.69 & 4 & 0.10 & \\
\hline Category 20 & -0.22 & 0.24 & 0.85 & 1 & 0.36 & 0.80 \\
\hline Category 30 & -0.09 & 0.22 & 0.17 & 1 & 0.68 & 0.91 \\
\hline Category 40 & -0.02 & 0.22 & 0.01 & 1 & 0.94 & 0.99 \\
\hline Category 50 & -0.49 & 0.23 & 4.66 & 1 & 0.03 & 0.61 \\
\hline Greenspace Cover & & & & & & \\
\hline Category 10 & & & 7.17 & 4 & 0.13 & \\
\hline Category 20 & 0.07 & 0.25 & 0.09 & 1 & 0.77 & 1.07 \\
\hline Category 30 & -0.51 & 0.29 & 3.11 & 1 & 0.08 & 0.60 \\
\hline Category 40 & 0.44 & 0.24 & 3.29 & 1 & 0.07 & 1.53 \\
\hline Category 50 & 0.01 & 0.24 & 0.00 & 1 & 0.98 & 1.01 \\
\hline Social Deprivation & & & & & & \\
\hline Category 10 & & & 217.56 & 4 & 0.00 & \\
\hline Category 20 & -1.17 & 0.44 & 7.14 & 1 & 0.08 & 0.31 \\
\hline Category 30 & -0.71 & 0.34 & 4.45 & 1 & 0.04 & 0.49 \\
\hline Category 40 & 0.79 & 0.29 & 7.68 & 1 & 0.06 & 2.21 \\
\hline Category 50 & 1.98 & 0.28 & 51.147 & 1 & 0.00 & 7.23 \\
\hline Material Deprivation & & & & & & \\
\hline Category 10 & & & 144.52 & 4 & 0.00 & \\
\hline Category 20 & -0.27 & 0.25 & 1.22 & 1 & 0.27 & 0.76 \\
\hline Category 30 & -0.14 & 0.25 & 0.32 & 1 & 0.57 & 0.87 \\
\hline Category 40 & 0.18 & 0.22 & 0.65 & 1 & 0.42 & 1.19 \\
\hline Category 50 & 1.58 & 0.17 & 85.42 & 1 & 0.00 & 4.86 \\
\hline Noise & & & & & & \\
\hline Category 10 & & & 8.23 & 3 & 0.04 & \\
\hline Category 20 & 0.38 & 0.18 & 4.31 & 1 & 0.04 & 1.46 \\
\hline Category 30 & 0.64 & 0.24 & 7.46 & 1 & 0.01 & 1.90 \\
\hline Category 40 & 1.22 & 1.04 & 1.38 & 1 & 0.24 & 3.38 \\
\hline Constant* & -2.07 & 0.33 & 39.72 & 1 & 0.00 & 1.26 \\
\hline Tests & & & $\begin{array}{l}\text { Wald's } \\
\mathbf{X}^{2}\end{array}$ & DF & Significance & \\
\hline Overall Model Evaluation & & & & & & \\
\hline Omnibus Test & & & 533.59 & 20 & 0.00 & \\
\hline $\begin{array}{l}\text { Goodness of fit test } \\
\text { Hosmer \& Lemeshow }\end{array}$ & & & 2.93 & 8 & 0.94 & \\
\hline Cox and Snell $R^{2}=0.13$ and & & & & & & \\
\hline
\end{tabular}


A goodness of fit statistic of importance is the Hosmer \& Lemeshow (H-L) test (Table 4.6.2). This assesses the fit of the logistic model against actual outcomes. The H-L test result for this model yielded an $\mathrm{X}^{2}(8)$ of 2.93 and was insignificant $(\mathrm{p}>0.05)$. This suggests that the model was fit to the data well. Two additional descriptive measures of goodness of fit were the Cox and Snell and Nagelkerke R-squared indices (Table 4.6.2). These are pseudo $r$ squared indices that were used supplementary to the H-L goodness of fit test.

The Table 4.6 .3 below displays the validity of the predicted probability. The binary value of 1 represents that public housing is present and 0 represents no public housing. The overall correct prediction of $91.30 \%$. This is very high because of the disproportionate amount of dissemination areas within the two groups. This is a limitation that introduced bias into the results displayed in the table below. Furthermore, the false positive classification rate of $7.22 \%$ and a false negative rate of $50 \%$. The difference within these rates is also attributed to the amount of cases within each of the binary categories of public housing - where there are significantly more nonpublic housing cases than public housing cases. The measure of the proportion of correctly classified events (public housing) was calculated as 19.70\%. This is low because of the disproportionate number of cases within the groups - there are very little public housing events comparatively. As well, the proportion of correctly classified non-events (non-public housing) was calculated as $98.10 \%$. Similarly, this is very high because of the large amount of cases within the non-public housing grouping. 


\begin{tabular}{lllcl}
\hline & Observed & \multicolumn{2}{c}{ Precited } & Percentage Correct \\
\cline { 1 - 4 } Step 1 & Binary & 0 & 1 & \\
\cline { 2 - 5 } & 0 & 3302 & 63 & 98.10 \\
\cline { 2 - 5 } & 1 & 257 & 63 & 19.70 \\
\hline Overall Percentage & & & 91.30
\end{tabular}

False positive $=3302 /(3302+257)=7.22 \%$. False negative $=63 /(63+63)=50.00 \%$.

The predicted probability of dissemination areas containing public housing was calculated from the logistic regression model (Figure 4.6.1). High probability areas are associated with events and the low probability areas are associated with non-events. Areas in dark blue on the Figure below, are the predicted public housing DA's. The map appears to accurately predict the dissemination areas where public housing is throughout Toronto. The regression model was able to predict the location of public housing based on the environmental exposures with high accuracy. 


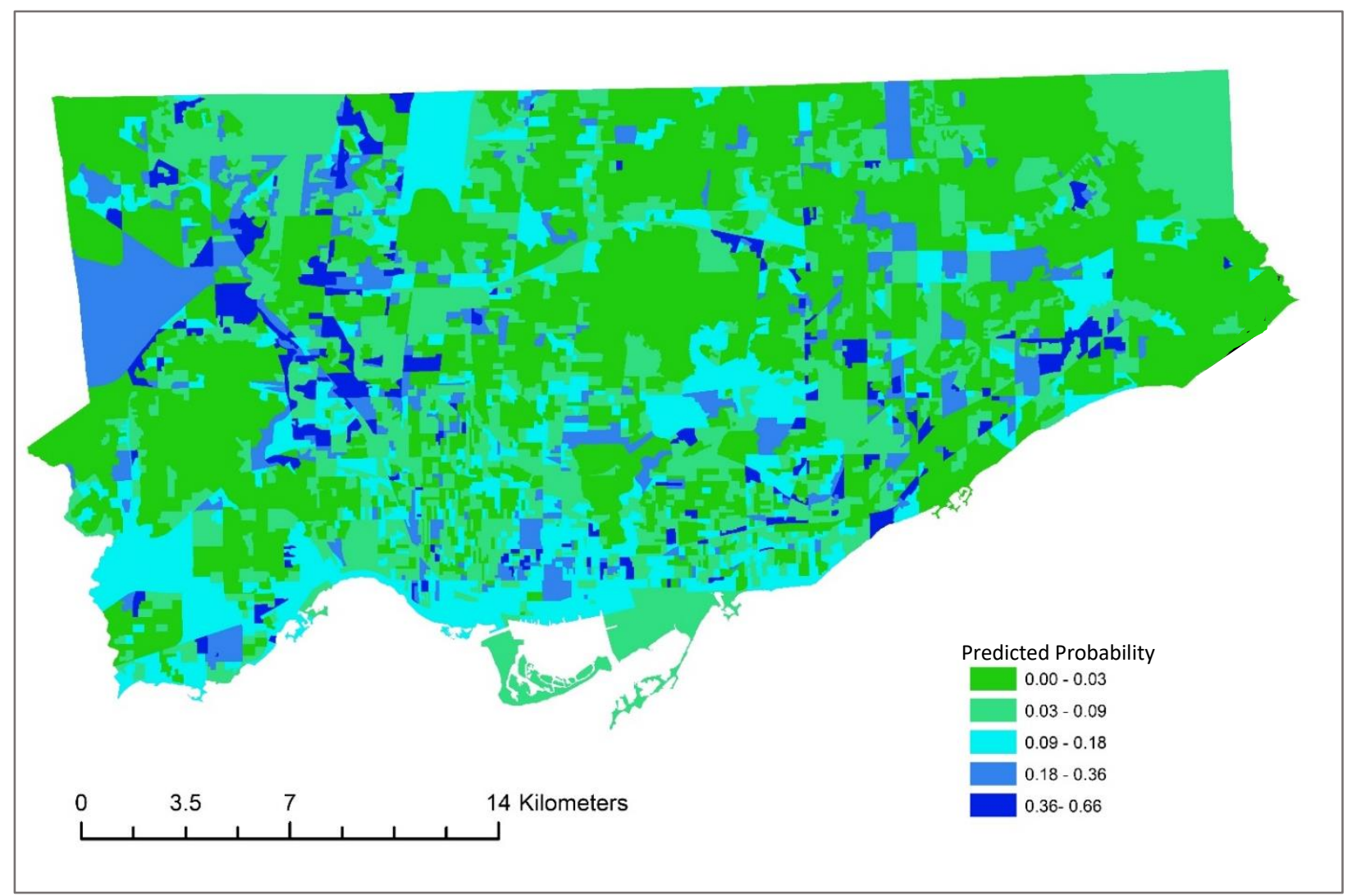

Figure 4.6.1. The predicted probability of public housing dissemination areas in Toronto, results from the logistic regression model.

\subsection{DISCUSSION}

The Toronto Community Housing Corporation was established in order to provide affordable and safe housing for low income families and individuals (TCHC, n.d.). The results of this study conclude that the current public housing units are situated in areas of high vulnerability to environmental exposures. Due to high housing costs, low incomes and the limited supply of public housing units, the neighbourhood and housing choices of those in need are very limited in Toronto (Boston College, 2013; DeLuca, Garboden \& Rosenblatt, 2013; Sylvestre, 2018; Toronto Public Health, 2016). It has been determined that the current housing developments are in physically detrimental conditions; however additionally, this research has determined that the environmental conditions surrounding public housing units are harmful. 
This research was particularly important because the population within public housing are more vulnerable to the negative health outcomes associated with high environmental exposure, because of their socioeconomic status (Vlachokostas et al., 2013; Olden et al., 2014; Helbich, 2018; Chueng \& Jim, 2019; Shmool et al., 2014). The selected environmental exposure data: air pollution, noise pollution, lack of access to greenspace, and high material and social deprivation, were selected because of their associated harmful health implications. As well, some research indicates that these environmental exposures have an additive negative effect on human health (Sexton \& Hattis, 2007). Nitrogen dioxide, as air pollution, has many effects on human health and the natural environment (Ontario, 2016) and, the major sources include: road vehicles, and other means of transportation (Parent et al., 2013; Fuks et al., 2017; Brook et al., 2004). The World Health Organization (2018) outlines that that only 40 micrograms per cubic meter of nitrogen dioxide are associated with negative health impacts on humans. The result of this study demonstrated that the highest estimated values of nitrogen dioxide exceeded $35 \mathrm{ppb}$ (65.8 micrograms per cubic meter) in Toronto. This is a very high average considering the World Health Organization's guidelines previously outlined. The health implications associated with higher levels of nitrogen dioxide are amplified, and include lung cancer, respiratory infection, stroke, and heart disease (WHO, 2018). Similarly, environmental noise is a significant issue for human health (Toronto Public Health, 2017); therefore, this is an important issue to study in Toronto. The health impacts of noise pollution range from sleep disturbance, stress, increased blood pressure, to mortality (Wolfgang Babisch, 2002; Toronto Public Health, 2017). These health impacts are concerning when noise levels exceed an average of $40 \mathrm{dBA}$ at night (World Health Organization, 2009); for urban centers (where higher noise levels are expected), $55 \mathrm{dBA}$ at night. Nightime noise was selected because of the significant effects on overall health and, in order to ensure exposure, 
due to high probability that at nighttime hours residents are within their own DA. Alarmingly, a study by Recio et al. (2016), found a 2.4 percent increase in the chance of mortality when nightime noise levels increased by $1 \mathrm{dBA}$ between $58.7-76.3 \mathrm{dBA}$, for those older than 65 . This study found that the maximum nightime noise levels estimated in Toronto were as high as $78 \mathrm{dBA}$. Similarly to air pollution, the nighttime noise levels in Toronto are within a dangerously high range and, are concerning for the wellbeing of those in proxmity to these levels (Toronto Public Health, 2017; World Health Organization, 2009).

The social deprivation index reflects the deprivation of relationships amongst individuals within their family, work and community (Metge et al., 2009). Specifically, the index is calculated based on the proportion of people living alone, moved within the past 5 years, separated or divorced etc. (Metge et al., 2009). The deprivation factor calculated from this assumes that those who live alone, who have recently moved or are separated/divorced, are subjected so social isolation or deprivation. However, it is very difficult to quantify social deprivation on a large scale based on these measures. As those who live alone or are separated could have very strong relationships with those at work or in their community, as well, those who live with a partner and haven't moved could be subjected to a high amount of social deprivation, abuse or isolation. This is a limitation as there are socioeconomic factors that cannot be fully calculated in equations; however, the social deprivation index has been used within many credible studies (Metge et al., 2009; Brownell et al., 2012; Fransoo et al., 2013). Social deprivation is an important measure, as socioeconomic determinants of health affect the vulnerability of populations to environmental exposure (Pearce \& Smith, 2003). There doesn't appear to be any definitive spatial patterns of social deprivation across Toronto, most likely because of factors such as social capital and subjectivity (Metge et al., 2009; Wikinson, 2007). The material deprivation index of Toronto 
dissemination areas is a measure of the average household income, unemployment rate (15 and older) and the population 15 or older without a high school diploma (Metge et al., 2009). The measures used to calculate material deprivation assume that those without a high school diploma, who are unemployed and who have a lower household income are not as materially privileged as others may be. Together these metrics do a good job of calculating the overall material deprivation of those in Toronto (Fransoo et al., 2013; Brownell et al., 2012; Metge et al., 2009). The material deprivation follows very similar patterns as income across Toronto, which makes sense since it measures material wealth.

Finally, the accessibility to beneficial greenspace was used as an exposure variable in this analysis. The proximity of greenspace to residents is strongly associated with the health benefits, where closer greenspaces are associated with stronger health benefits (Toronto Public Health, 2015). The study Natural England (2010) found that the benefits of greenspace were optimized in proximity of greenspaces more than 2 hectares in size. However, Toronto is a very populated urban center; access to more than 2 hectares of greenspace would be difficult for residents of the downtown core. Therefore, 1 hectare or more of greenspace was chosen as beneficial greenspace for this study. The results display that greenspace accessibility was very limited based on the methods of this study. It's suggested that greenspace accessibility should be re-analyzed with a smaller parameter of greenspace, because the majority of the dissemination areas contained no greenspace more than 1 hectare in size (approximately 2000 DA's contained $0 \%$ cover of accessible beneficial greenspace). As well, more in depth research should be conducted to determine if smaller areas of greenspace produce the same benefits as larger areas, to populations in close proximity. The results did find that dissemination areas far from the downtown core contained up to $80 \%$ cover of greenspace. This difference highlights the unequal accessibility to 
greenspace in Toronto. A limitation of utilizing percent cover as the accessibility metric is that dissemination areas are population-based geographies, and therefore, the sizes of dissemination areas increase further form the downtown core. This introduces error into the calculated percent cover of accessibility. Toronto Public Health (2015) reports that vulnerable groups, such as those in low income households, gain the most benefits from increased access to greenspaces. The study reports that greenspace reduces mortality rates, obesity, cardiovascular disease, birth outcomes and mental health significantly within low income, minority populations (Toronto Pubic Health, 2015). Accessibility to greenspace is important to study, as it has been shown to buffer the negative effects of other environmental stressors and poor housing quality (Jones-Rounds et al., 2013). It would be important for public housing developments to be in close proximity to high greenspace cover in order to uphold the health and wellbeing of residents, despite environmental and housing conditions (Jones-Rounds et al., 2013; Pagliaro, 2017).

This study additionally aimed to model the probability of public housing being present in dissemination areas in Toronto, based on the environmental exposure levels. More specifically, if incidences of high levels of nitrogen dioxide, noise, social deprivation, material deprivation and low access to greenspaces could predict the outcome of public housing presence within dissemination areas. The results of the logistic regression modelling determined that the high levels of exposures successfully predicted the presence of public housing within dissemination areas. This supports environmental justice theory, that the burdens of environmental stress are unequally affecting the vulnerable populations living in public housing developments.

Using a GIS-based framework in combination environmental justice was useful to visualize the distribution of multiple environmental stress in relation to public housing units. Geographic information systems have been used previously to study health and environmental issues (Fisher 
et al., 2005; Jarrett et al., 2005; Maantay, 2007; Sheppard et al., 1999), as it is a useful tool for analyzing spatial patterns across large landscapes (Sheppard et al., 1999). As well, GIS technology is useful in order to accurately and efficiently assess the vulnerability of geographic areas to environmental exposure risks and human health impacts (Burgos et al., 2017; Choudhary et al., 2018; Chakraborty, Schweitzer \& Forkenbrock, 1999). Evaluating the environmental exposure vulnerability in Toronto, using GIS, allowed multiple datasets to be analyzed in the context of geographic areas of interest (dissemination areas with public housing). The inherently spatial nature of the distribution of environmental exposure across landscapes makes GIS particularly well suited to enhance such analysis. This significantly contributed to the current knowledge gaps surrounding the environmental exposure levels across the city of Toronto. Furthermore, the results of this study are also important to environmental justice scholarship, as they highlight the distributional inequities of environment burden upon Toronto public housing neighbourhoods. The objective of environmental justice is to ensure that adverse environmental or human health effects of government activities, do not fall disproportionately affect minority or low-income populations (Chakraborty, Schweitzer \& Forkenbrock, 1999). As it has been seen extensively in environmental justice literature, that low income communities often bear the disproportionate weight of environmental stress, such as pollution (Tufts University, 2004). This study found that that high vulnerability to environmental exposure and the location of public housing follow similar patterns across Toronto. Moreover, the combination of effects of exposure and socioeconomic susceptibility indicate a very high vulnerability to the health effects of environmental exposures (Pinault et al., 2016; Shmool et al., 2014).

The general approach and visualization of the results of this research can be used to aid the TCHC and the municipal government to evaluate how and where oversight and improvements 
should be implemented towards Toronto public housing. Currently, the locations of public housing are within extremely vulnerable areas, and are subjected to harmful levels of environmental exposures. In order to make large improvements towards environmental and health equity, the city of Toronto should consider relocation of the public housing units within the extremely vulnerable areas. A participatory gis approach to the distribution of this research is also very important, in order to make the results of this study transparent for all community members. This research could be used by those within public housing units for empowered demand driven activism towards changes and relocations of units. Therefore, information exchange and education based on these findings for the populations of public housing is also very important. Further research should explore effective approaches for gis capacity building within the city of Toronto, with particular emphasis on accessibility for low income and minority populations.

\subsection{CONCLUSION AND RECOMMENDATIONS}

In conclusion, environmental justice research seeks to ensure that environmental burdens do not disproportionately burden minority or low-income populations (Chakraborty, Forkenbrock \& Schweitzer, 1999). This paper contributes to this objective, using a GIS framework, in order to assess and highlight the disproportionate impacts of environmental stressors on public housing units. This research successfully worked to enhance the visibility of injustices surrounding environmental stress and public housing in Toronto. Currently, there is limited access to safe, stable and affordable housing within Toronto, despite the efforts of the TCHC (Toronto, 2018). In

order for future improvements, a new Toronto Housing Strategy 2020-2030, has begun implementing new action plans to address the housing needs and concerns of Toronto residents. The strategy will work to increase the supply and improve the oversight of public housing developments (Toronto, 2018). This research provides insight into the geographic vulnerability to 
environmental exposure, and could recommend well-suited locations for public housing expansion. As well, this research recommends where changes or relocation should take place within the current inventory of housing locations. Most importantly, this research shines a light over the justice issue at hand regarding public housing and environmental exposure. Environmental justice and public housing advocacy both take place against the backdrop of disparities in wellbeing, municipal fragmentation and disinvestment (Haberle, 2017). This research recommends that the city of Toronto should implement improved oversight; in regards to providing housing choices for vulnerable populations away from environmental burdens, in order to diminish these disparities. As well, the city of Toronto should invest more time and money into fixing this exposure discrepancy inflicted upon vulnerable populations. Furthermore, this research should be of interest to municipalities across Canada, in order to provide a framework and incentive to consider if local vulnerable populations within their public housing systems are being disproportionately affected by adverse environmental exposure levels. Overall, this research provides insight into the disparities of environmental exposure with a novel focus on public housing, and works to ensure that action and changes are realized in order to diminish and/or extinguish these inequalities. 


\section{REFERENCES}

Andrews, J., Mueller, M., Newman, S., Magwood, G., Ahluwalia, J., White, K. \& Tingen, M. 2014. The association of individual and neighbourhood social cohesion, stressors and crime on smoking status among african-american women in southeastern us in subsidized housing neighbourhoods. Journal of Urban Health, 91(6), 1158-1174.

Angelsen, A. and Dokken, T. 2018. Climate exposure, vulnerability and environmental reliance: a cross section analysis of structural and stochastic poverty. Environmental and Development Economics, 23, pp. 257-278. Retrieved from https://journals-scholarsportalinfo.ezproxy.lib.ryerson.ca/pdf/1355770x/v23i0003/257_cevaeraosasp.xml

Apparicio, Seguin \& Naud. 2008. The quality of the urban environment around public housing buildings in Montreal an objective approach based on GIS and multivariate statistical analysis. Social indicators research, 86(3), p.355-380

Babisch, W. 2011. Cardiovascular effects of noise. Noise \& Health, 13(52), pp. 201-204. Retrieved from https://search-proquest-com.ezproxy.lib.ryerson.ca/docview/865972242?pqorigsite $=$ summon

Basner, M., Babisch, W., Davis, A., Brink, M et al. 2014. Auditory and non-auditory effects of noise on health. Lancet, 383(9925), pp. 1325 - 1332. Retrieved from https://www.ncbi.nlm.nih.gov/pmc/articles/PMC3988259/

Bavaghar, Pir. 2015. Deforestation modelling using logistic regression and GIS. Journal of Forest Science, 61(5), pp. 193-199. $\quad$ Retrieved from https://www.agriculturejournals.cz/publicFiles/78_2014-JFS.pdf

Beder, Michaela \& Ritts, Madeleine. Dec 4, 2017. it's time to decalre an emergency on homelessness in Toronto. The Star. https://www.thestar.com/opinion/contributors/2017/12/04/its-time-to-declare-anemergency-on-homelessness-in-toronto.html

Bell, K. Environmental justice in Cuba. Critical Social Policy 31(2), pp 241 - 265. Retrieved from https://journals-sagepub-com.ezproxy.lib.ryerson.ca/doi/pdf/10.1177/0261018310396032

Bilasco, S., Govor, C., Rosca, S., Vescan, L., Filip, S. \& Fodorean, I. 2017. GIS model for identifying urban areas vulnerable to noise pollution: case study. Frontiers of Earth Science, 11(2), p.214-228

Boori, M.S., Choudhary K., Kupriyanov, A. 2019. Mapping groundwater potential zone based on remote sensing and GIS techniquesL a case study of Kalmykia, Russia

Boston College. 2013. For low-income families, substandard housing takes toll on children. Health and medicine week. p.1314 
Brook, RD., Franklin, B., Cascio, W., Hong, YL, Howard, G., Lipsett, M., Luepker, R., Mittleman, M., Samet, J., Smith, SC. And Tager, I. 2004. Air pollution and cardiovascular disease a statement for healthcare professionals from the expert panel on population and prevention science of the American Heart Association. Circulation, 109 p. 2655-2671.

Brownell M, Chartier M, Santos R, Ekuma O, Au W, Sarkar J, MacWilliam L, Burland E, Koseva I, Guenette W. How are Manitoba's Children Doing? Winnipeg, MB: Manitoba Centre for Health Policy, 2012

Burgos, S., Madrid, M.A., Maldonado, A., Medina, F. \& Iglesias, V. Integrating multivariate and geostatistical analyses for assessing the socio-environmental vulnerability of children in the vacinity of a contaminated site. International journal of environmnetal health research, 28(6), 642-652

CanMap Postal Code Suite v2015.3. [computer file] Markham: DMTI Spatial Inc., 2015

Chakraborty, J., Schweitzer, LA. And Forkenbrock, DJ. Using GIS to assess the Environmental Justice consequences of transportation system changes. 2002. Transactions in GIS, 3(3), p.239-258.

Choudhary, K., Boori, M. \& Kupriyanov, A. 2017. Spatial modelling for natural and environmental vulnerability through remote sensing and GIS in Astrakhan, Russio. The Egyptian Journal of Remote sensing and Space Sciences, 21. pp. 139-147

City of Toronto. 2015. Green City: Why Nature Matters to Health. Retrieved from https://www.toronto.ca/legdocs/mmis/2015/hl/bgrd/backgroundfile-83420.pdf

CMHC, n.d. Canadian Mortgage and Housing Corporation. Available online: https://www.cmhcschl.gc.ca/

Craig, C. (2007) Toronto's New Social Housing Waiting List: Putting the choice based rental model into local context. (Masters in Urban Development) Ryerson University, Toronto Canada.

Cutter, S. Race, class and environmental justice. 1995. Progress in Human Geography 19 (1), pp. 111-122. Retrieved from https://journals-sagepubcom.ezproxy.lib.ryerson.ca/doi/abs/10.1177/030913259501900111

DeLuca, S., Garboden, P. \& Rosenblatt, P. 2013. Segregating shelter: how housing policies shape the residential locations of low-income minority families. The ANNALs of the American Acadaemy of Political and Social Science, 647(1), p.268-299.

Dunn, J.R. 2002. Housing and inequalities in health: a study of socioeconomci dimensions of housign and selfreported health from a survey of Vancouver residents J. Epidemiol Community Health, 56, p. 671-681. 
Duong, D. (2018, November). Poverty Disproportionately Affects Marginalized Communities in Canada. Canadian Living, Retrieved from https://www.canadianliving.com/life-andrelationships/community-and-current-events/article/poverty-disproportionately-affectsmarginalized-communities-in-canada

Eric Sheppard, Helga Leitner ,Robert B McMaster and Hongguo Tian. GIS based measures of environmental equity: Exploring their sensitivity and significance. 1999. Journal of Exposure Analysis and Environmental Epidemiology 9, pp 18-28. Retrieved from https://www-nature-com.ezproxy.lib.ryerson.ca/articles/7500023.pdf

Ernstson, H. 2012. The social production of ecosystem services: A framework for studying environmental justice and ecological complexity in urbanized landscapes. Journal of Landscape and Urban Planning, 109, pp.7-17. Retrieved from: https://journalsscholarsportal-info.ezproxy.lib.ryerson.ca/pdf/01692046/v109i0001/7_tspoesaeciul.xml

Fisher, J., Kelly, M. and Romm. J. Scales of environmental justice: combining GIS and spatial analysis for air toxics in West Oakland, California. Health \& Place 12(4), pp. $701-714$. Retrieved from https://www.sciencedirect.com/science/article/abs/pii/S1353829205000614

Florida, R. August 8, 2018. Toronto Can solve its affordable housing crisis. Here's how. The Star. https://www.thestar.com/opinion/contributors/2018/08/08/solutions-for-solving-torontosaffordable-housing-crisis.html?li_source=LI\&li_medium=star_web_ymbii

Fransoo R, Martens P, The Need to Know Team, Prior H, Burchill C, Koseva I, Bailly A, Allegro E. The 2013 RHA Indicators Atlas. Winnipeg, MB: Manitoba Centre for Health Policy, 2013

Fuks, KB et al. 2017. Long-term exposure to ambient air pollution and traffic noise and incident hypertension in seven cohorts of the European study of cohorts for air pollution effects (ESCAPE). European Heart Journal, 38(13) p. 982-990.

Guyadeen, D.R. Affordable housing within a post-welfare state: The case of Toronto. MPA Research Report, University of Western Ontario. 2011

Haberle, M. 2017. Fair Housing and Environmental Justice: New Strategies and Challenges. Journal of Affordable Housing, 26(2), p.271-280.

Hackworth, J. \& Moriah, A. 2006. Neoliberalism, contigency and urban policy: the case of social housing in Ontario. International journal of urban and regional research, 30(3), p.510-527

Halperin, D. Environmental noise and sleep disturbances: A threat to health? 2014. Sleep Science 7(4), pp. 209-212. Retrieved from https://www.ncbi.nlm.nih.gov/pmc/articles/PMC4608916/ 
Harlan, S., Declet-Narreto, J., Stefanov, W. \& Petitti, D. Neighbourhood effects of heat deaths: social and environmental predictors of vulnerability in Maricopa County, AZ. Environmental Health perspectives, 121(2), 197.

Heckert, M. (2013). Access and Equity in greenspace provision: a comparison of methods to access the impacts of greening vacant land. Transactions in GIS, 17(6), pp. 808-827. Retrieved from https://journals-scholarsportalinfo.ezproxy.lib.ryerson.ca/details/13611682/v17i0006/808_aaeigptiogvl.xml

Helbich, M. 2018. Mental Health and Environmental Exposures: An Editorial. Int. J. Envron Research Public Health, 15(10), 2207

Helbich, M. 2018. Toward dynamic urban environmental exposure assessments in mental health research. Environmental research, 161, p.129-135

Hystad P, Setton E, Cervantes A, Poplawski K, Deschenes S, Brauer M, et al. 2011. Creating National Air Pollution Models for Population Exposure Assessment in Canada. Environ. Health Perspect. 119:1123-1129; doi:10.1289/ehp.1002976.

Ibem, E., Opoko, P. \& Aduwo, E. 2017. Satisfaction with neighbourhood environments in public housing: evidence from ogun state, Nigeria Social indeces research. 130, p. 733-757

Jarrett, M., Burnett, R., Kanaroglou,P., Eyles, J., Finkelstein, N., Giovis, C. and Brook, J. A GIS environmental justice analysis of particulate air pollution in Hamilton, Canada. 2001. Environment and Planning 33, pp. 955-973. Retrieved from https://journals-sagepubcom.ezproxy.lib.ryerson.ca/doi/pdf/10.1068/a33137

Jarrett, M., Burnett, R.T., Kanaroglou, P., Eyles, J., Finkelstein, N., Giovis, C. \& Brook, J.R. A GIS-environmental justice analysis of particulate air pollution in Hamilton, ON. Environment and Planning, 33, p.955-973

Jarrett, M., Buzzelli, M., Burnett, R.T. \& DeLuca, P.F. Particulate air pollution, social confounders and mortality in small aras of an industrial city. 2005. Social Science and Medicine, 60(12), p. $2845-2863$

Jennings, V., Larson, L. \& Yun, J. (2016 Feb). Advancing Sustainability through Urban Green Space: Cultural Ecosystem Services, Equity, and Social Determinants of Health. International Journal of Environmental Research and Public Health, 13(2), pp. 1-15. Retrieved from https://search-proquestcom.ezproxy.lib.ryerson.ca/docview/1771772340?pq-origsite=summon 
Jones-Rounds., M., Evans, G.W. and Braubach, M. 2014. The interactive effects of housing and neighbourhood quality on psychological well-being. Journal of Epidemiologiy and Community Health, 68(2), p. 171-175.

Kwan, M. The limits of the neighbourhood effect: contextual uncertainties in geographic, environmental health and social science research.2018. Annals of the american association of geographers

Lakes, T., Bruckner, M., and Kramer, A. Development of an environmental justice index to determine socioeconomic disparities of noise pollution and greenspace in residential areas in Berlin. 2014. Journal of Environmental Planning and Management 57(4), pp. 538-556. Retrieved from https://journals-scholarsportalinfo.ezproxy.lib.ryerson.ca/pdf/09640568/v57i0004/538_doaejisiraib.xml

LaToria, S. \& Buchanan, S.D. 2019. Childhood Lead Poisoning: A Perpetual Environmental Justice Issue? Childhood Lead Poisoning and Environmental Justice, 23(1), pp.115-120. Retrieved from http://ovidsp.dc1.ovid.com.ezproxy.lib.ryerson.ca/sp3.33.0b/ovidweb.cgi? WebLinkFrameset=1\&S=AAFKFPADGPACKCFIKPDKGFHOCP BJAA00\&returnUrl=ovidweb.cgi\%3f\%26Titles\%3dS.sh.22\%257c1\%257c100\%26FOR MAT\%3dtitle\%26FIELDS\%3dTITLES\%26S\%3dAAFKFPADGPACKCFIKPDKGFHO CPBJAA00\&directlink=http\%3a\%2f\%2fovidsp.dc1.ovid.com\%2fovftpdfs\%2fFPACKP HOGFFIGP00\%2ffs046\%2fovft\%2flive\%2fgv023\%2f00124784\%2f0012478420190100100019.pdf\&filename $=$ Childhood + Lead + Poisoning $\% 3 \mathrm{a}++\mathrm{A}+$ Perpetual + Environmental $+\mathrm{J}$ ustice+Issue \%3f.\&navigation_links=NavLinks.S.sh.22.1\&PDFIdLinkField=\%2ffs046\%2 fovft\%2flive $\% 2 \mathrm{fgv} 023 \% 2 \mathrm{f00124784 \% 2f00124784-201901001-}$ 00019\&link_from $=$ S.sh.22\%7c1\&pdf_key=B\&pdf_index $=$ S.sh.22\&D=ovft

Ma, J., Li, C., Kwan, M.P. and Chai, Y. A Mutlilevel Analysis of Percieved Noise pollution, geographic context and mental health in Beijing. 2018. International Journal of Environmental Research and Public Health 15(7), pp. 1 -18. Retrieved from https://www.ncbi.nlm.nih.gov/pmc/articles/PMC6068638/pdf/ijerph-15-01479.pdf

Maantay, J. Asthma and air pollution in the Bronx: Methodological and data considerations in using GIS for environmental justice and health research. 2007. Health \& Place 13(1), pp. 32-56.

Retrieved from https://www.sciencedirect.com/science/article/abs/pii/S1353829205000675

Maroko, A., Riley, R.W., Reed, M. \& Malcolm, M. 2013. Direct observation of neighbourhood stressors and environmental justice in the South Bronx, New York City. Population and Environment, 35(4), pp. 477-496. Retrieved from: https://link-springercom.ezproxy.lib.ryerson.ca/article/10.1007\%2Fs11111-013-0197-5 
Massey, R. 2004. Environmental Justice: Income, Race and Health. Global Development And Environment Institute, Tufts University.

McGirr, E., Skaburskis, A. \& Donegani, T. 2015. Expectations, preferences and satisfaction levels amongst new and long-term residents in a gentrifying Toronto neighbourhood. Urban Studies, 52(1), p.3-19

Messer, L.C., Jagai, J., Rappazzo, K. \& Lobdell, D. (2014, May). Environmental Health, 13(39), pp 1-22. Retrieved from https://ehjournal.biomedcentral.com/track/pdf/10.1186/1476$\underline{069 X-13-39}$

Metge, C., Chateau D., Prior H, Soodeen R. De Coster C, Barré L. Composite Measures/Indices of Health and Health System Performance. Winnipeg, MB: Manitoba Centre for Health Policy, August 2009

Mohai, P., Pellow, D. \& Roberts, J.T. 2009. Environmental Justice. Annual Review of Environment and Resources, 34, pp. 405-430. Retrieved from: https://www-annualreviewsorg.ezproxy.lib.ryerson.ca/doi/pdf/10.1146/annurev-environ-082508-094348

Munzel, T., Sorensen, M, Schmidt, F., Schmidt, E., Steven, S., Kroller-Schon, S. and Daiber, A. The adverse effects of environmental noise exposure on oxidative stress and cardiovascular risk. Antioxidants and Redox Signaling, 28(9), pp. 873-908.

Obsorne, N., Hawthorne, T., Dajun, D., Fuller, C. \& Stauber, C.2018. Mapping the Hidden Hazards: community led spatial data collection of street level environmental stressors in a degraded, urban watershed. International journal of environmental research and public health, 15(4), p.825

Oiamo, T., Lyginaah,I. \& Baxter, J. 2015. Cumulative effects of noise and odor annoyance on environmental and health related quality of life. Social science and medicine, 146, pp.191203

Oiamo, T., Davies, H., Rainham, D., Rinner, C., Drew, K., Sabaliauskas, K. and Macfarlane, R. 2018. A combined emission and receiptor-based approach to modelling environmental noise in urban environments. Environmental Pollution, 242, pp. 1387-1394.

Olden, K., Lin, YS., Gruber, D. and Sonawane, B. Epigenome: Biosensor of Cumulative Exposure to Chemical and Nonchemical Stressors Related to Environmental Justice. 2014. American Journal of Public Health_104 (10) pp 1816 - 1821. Retrieved from https://search-proquestcom.ezproxy.lib.ryerson.ca/docview/1564433001/fulltextPDF/DC05ACA4A5864A9EP Q/1? accountid=13631

Ontario. 2016. Ministry of Education. Available online http://www.edu.gov.on.ca/eng/parents/fci.html 
Oulahen, G., McBean, G., Shrubsole, D. and Change, S. 2018. Production of risk: multiple interacting exposures and unequal vulnerability in coastal communities. Regional Environmental Change, 3(19), pp. 867-877. Retrieved from https://link.springer.com/article/10.1007\%2Fs10113-018-1440-5

Pagliaro, J. May 23, 2017. Half of Toronto Community Housing homes to hit critical status within 5 years. The Star. Retrieved from https://www.thestar.com/news/city_hall/2017/05/23/half-of-toronto-community-housinghomes-to-hit-critical-status-within-five-years.html

Pagliaro, J. and Mathieu, E. June 25, 2019. About 1,400 of Toronto's subsidized housing units sit empty each day as city struggles with waiting list, auditor general says. The Star https://www.thestar.com/news/city_hall/2019/06/25/about-1400-of-torontossubsidized-housing-units-sit-empty-each-day-as-city-struggles-with-waiting-listauditor-general-says.html

Parent ME, Goldberg MS, Crouse DL, et al. 2013. Traffic related air pollution and prostate cancer risk: a case-control study in Montreal, Canada. Occupational Environmental Medicine, 70, 511- 518.

Pearce. J, Witten, K. \& Bartie, P. 2006. Neighbourhoods and health: a GIS approach to measuring community resource accessibility. Journal of Epidemiology and Community Health, 60(5), p.389-395.

Poulter, N.R., Hemingway, H. and Colhoun, H. 1998. Socio-economic status and blood pressure: an overview analysis. Journal of Human Hypertension, 12(2):91-110. doi: 10.1038/sj.jhh.1000558.

RBC Economics, 2017. Housing Trends and Affordability. Available online http://www.rbc.com/economics/economic-reports/pdf/canadian-housing/housemar2017.pdf

Recio, A., Linares, C., Banegas, JR. \& Diaz, J. 2016. The short-term association of road traffic noise with cardiovascular, respiratory, and diabetes-related mortality. Environmental Research, 150, pp. 383-390.

Ross, N., Oliver, L. \& Villeneuve, P. (2013, April). International Journal of Environmental Research and Public Health, 10(4), pp 1378-1391. Retrieved from https://search-proquestcom.ezproxy.lib.ryerson.ca/docview/1355249528/fulltextPDF/C6544ED8A8584487PQ/1 ?accountid=13631

Sampson, L., Dasgupta, K. \& Ross, N. (2014, June). The association between socio-demographic marginalization and plasma glucose levels at diagnosis of gestational diabetes. Diabetic Medicine, 31(12). Retrieved from https://onlinelibrary-wileycom.ezproxy.lib.ryerson.ca/doi/full/10.1111/dme.12529 
Schlosberg, D. 2007. Defining Environmental Justice: Theories, Movements, and Nature. Oxford Scholarship. Retrieved from https://www-oxfordscholarshipcom.ezproxy.lib.ryerson.ca/view/10.1093/acprof:oso/9780199286294.001.0001/acprof9780199286294-chapter-1

Sexton, K and Hattis, D. 2007. Assessing cumulative health risks from exposure to environmental mixtures - three fundamental questions. Environmental Health Perspectives, 115(5), pp. 825-832.

Retrieved from https://www.ncbi.nlm.nih.gov/pmc/articles/PMC1867955/?tool=pmcentrez\&report=abstract

Sheppard, E., Leitner, H., McMaster, R.B. and Tian, H. (1999) GIS-based measures of environmental equity: exploring their sensitivity and significant. Journcal of exposure analysis and environmental epidemiology, 9, 18-28.

Shmool, JLC., Kubzansky, LD., Newman, OD., Spengle, J., Shepard, P., and Clougherty, J. Social stressors and air pollution across New York City communities: a spatial approach for assessing correlations among multiple exposures. 2014. Environmental Health 13(91), pp 1 -15. Retrieved from https://ehjournal.biomedcentral.com/track/pdf/10.1186/1476-069X$\underline{13-91}$

Skelton, I. 1996. The Geographic Distribution of Social Housing in Ontario, Canada: Comparing Public Housing and Locally Sponsored, Third Sector Housing. Housing Studies, 11(2), pp. 189-206. Retrieved from https://journals-scholarsportalinfo.ezproxy.lib.ryerson.ca/pdf/02673037/v11i0002/189_tgdoshalstsh.xml

Statistics Canada. 2015. A Comparison of individual and area based socio-economic data for monitoring social inequities in health. 20(4). Retrieved from https://www150.statcan.gc.ca/n1/pub/82-003-x/2009004/article/11035/findings-resultatseng.htm

Stansfeld, S. 2015. Noise Effects on Health in the Context of Air Pollution Exposure. International Journal of Environmental Research and Public Health, 12(10), pp. 12735- 12760.

Sylvestre, J., Klodawsky, F., Gogosis, E., Ecker, J., Polillo, A., Czechowski, K., Agha, A., Shankar, S., To, M. Gadermann, A., Palepu, A. \& Hwang, S. 2018. Perceptions of Housing and Shelter among People with Histories of Unstable Housing in three Cities in Canada: A Qualitative Study. American Journal of Community Psychology, 61(1-3), pp. 445-458. Retrieved from https://onlinelibrary-wileycom.ezproxy.lib.ryerson.ca/doi/full/10.1002/ajcp.12243

Taylor, L. \& Hochuli, D.F. 2017. Defining greenspace: multiple uses across multiple disciplines. Landscape and urban planning, 158, p.25-38

TCH development quality https://docs.google.com/spreadsheets/d/1z4W_6u6WW8eSzKT0Qm6B8nq7Ho7MYQ6eK0fiOiVAW4/edit\#gid=782374696 
Toronto Community Housing. 2017. Our way forward: annual report. Retrieved from https://www.torontohousing.ca/about/annualreports/Documents/AnnualReport17\%20Digital\%20JULY172017.pdf

Toronto Public Health, 2015. Green City: why nature matters to health. Retrieved from https://www.toronto.ca/legdocs/mmis/2015/hl/bgrd/backgroundfile-83420.pdf

Toronto Public Health, 2016. Housing and health: unlocking opportunity. Retrieved from https://www.toronto.ca/legdocs/mmis/2016/hl/bgrd/backgroundfile-97428.pdf

Toronto Public Health, 2017. Nosie and Your Health. Retrieved from https://www.toronto.ca/community-people/health-wellness-care/health-programsadvice/noise-and-your-health/

Toronto. 2018. Affordable Housing - Housing Affordability, Availability and Repair. Retrieved from https://www.toronto.ca/city-government/council/2018-council-issue-notes/torontoshousing/housing-affordability-availability-repair/

Vakili-Zad, C. 2004. Housing or Dehousing - the Public Housing Waitig List, Eviction, and the Homeless in Toronto, Canada. Journal of Affordable Housing and Community Development Law, 14(1), pp.63-81. Retrieved from: https://heinonlineorg.ezproxy.lib.ryerson.ca/HOL/Page?collection=journals\&handle=hein.journals/jrlaff14 \&id=78\&men_tab=srchresults

Vlachokostas, C., Banias, G., Athanasiadis, A., Achillas, C., Akylas, V \& Noussiopoulos, N. 2014. Cense: a tool to assess combined exposure to environmental health stressors in urban areas. Environmental International, 63, 1-10.

Weichenthal S, Pinault L, Burnett RT. (2017) Impact of Oxidant Gases on the Relationship Between Outdoor Fine Particulate Air Pollution and Nonaccidental, Cardiovascular, and Respiratory Mortality. Scientific Reports 7, Article number: 16401. Doi:10.1038/s41598017-16770-y

Wilkinson, RG \& Pickett, KE. 2007. The problems of relative deprivation: why some societies do better than others. Social Science and Medicine, 65(9). Retrieved from https://www.ncbi.nlm.nih.gov/pubmed/17618718

World Health Organization. 2018. Environmental Noise Guidelines for the European Region. Retrieved from http://www.euro.who.int/_data/assets/pdf_file/0009/383922/noiseguidelines-exec-sum-eng.pdf

Young, T and Bruce, B. 2003. Decisions adverse to household: protecting social housing tenants under the Social Housing Reform Act and the Tenant Protection Act. Journal of law and social policy, 18, p.1. 